\title{
Summer maximum temperature over the gulf cooperation council states in the twenty-first century: multimodel simulations overview
}

\author{
Mansour Almazroui ${ }^{1}$
}

Received: 6 January 2020 / Accepted: 3 June 2020 / Published online: 15 June 2020

(C) The Author(s) 2020

\begin{abstract}
The present study analyzes the Survivability for a Fit Human Threshold (SFHT) maximum temperature during the summer (June-August) over the six Middle Eastern countries known as the Gulf Cooperation Council (GCC) in the twenty-first century. An ensemble of three dynamically downscaled global climate models available from the Coupled Model Intercomparison Project Phase 5 (CMIP5) under the Representative Concentration Pathways (RCPs) RCP4.5 and RCP8.5 emission scenarios is used to analyze the future climate (2006-2099) over the region. The ground-truth air temperature for ten major cities across the GCC countries is utilized for model evaluation and to estimate the model-simulated temperature biases. Both positive and negative biases found during the present climate (1976-2005) are used to adjust the future temperature changes. These adjustments show that the summer maximum temperature is likely to increase continuously for most cities in the GCC countries at the rate of about $0.2^{\circ} \mathrm{C}\left(0.6^{\circ} \mathrm{C}\right)$ per decade under RCP4.5 (RCP8.5) for the future period (2020-2099), which is significant at the $99 \%$ confidence level. For RCP8.5, the adjusted summer maximum temperature may exceed the SFHT limit of $42{ }^{\circ} \mathrm{C}$ in five capital cities of the GCC states and four major cities of Saudi Arabia. The projections based on adjusted values indicate that the average summer maximum temperature should not exceed $52{ }^{\circ} \mathrm{C}$ in any city investigated by the end of the twenty-first century. The daily maximum temperature is projected to exceed $55^{\circ} \mathrm{C}$ in some cities in the $\mathrm{GCC}$ region by the end of the twenty-first century under a business-as-usual scenario that seems to be unrealistic if the biases are not taken into account. It is highly recommended that the GCC states should coordinate their efforts to respond appropriately to these projections using large ensembles of multimodel simulations while allowing for the associated uncertainty.
\end{abstract}

Keywords Summer temperature $\cdot \mathrm{CMIP} 5 \cdot \mathrm{RCPs} \cdot \mathrm{RegCM} 4 \cdot$ Gulf Cooperation Council

\section{Introduction}

There is a well-recognized link between increased ambient summer temperatures and adverse health outcomes. People in the Gulf Cooperation Council (GCC) countriesconsisting of the Kingdom of Saudi Arabia, United Arab Emirates, Kingdom of Bahrain, State of Kuwait, Sultanate of Oman, and Qatar - are worried about the "survivability for a fit human threshold (SFHT)" temperature in the coming decades, particularly at the end of the twenty-first century. The

Responsible Editor: Zhihua Zhang

Mansour Almazroui mansour@kau.edu.sa

1 Center of Excellence for Climate Change Research/Department of Meteorology, King Abdulaziz University, PO Box 80208, Jeddah 21589, Saudi Arabia
SFHT is the highest temperature that is tolerable for a healthy human under well-ventilated outdoor conditions (Im et al. 2017). People who live in the GCC states have a sound scientific reason to worry, because the Intergovernmental Panel on Climate Change (IPCC), in its Fifth Assessment Report (AR5), provided a clear indication of increasing global temperature (IPCC 2013) that also projects a steady increase in local temperature over this region. The temperature threshold varies from place to place and from season to season, because of the variability of relative humidity as well as prevailing wind speed and direction. In the current climate (19762015), the wet-bulb temperature (which accounts for the effect of both environmental heat and moisture) rarely exceeds 31 ${ }^{\circ} \mathrm{C}$ for a relative humidity of $63 \%$ over the Arabian Peninsula (Im et al. 2017; Dee et al. 2011). In the future, there are likely to be many locations over the Arabian Peninsula where the temperature may exceed the SFHT limit (Lelieveld et al. 2016). Therefore, it makes sense to investigate the SFHT at 


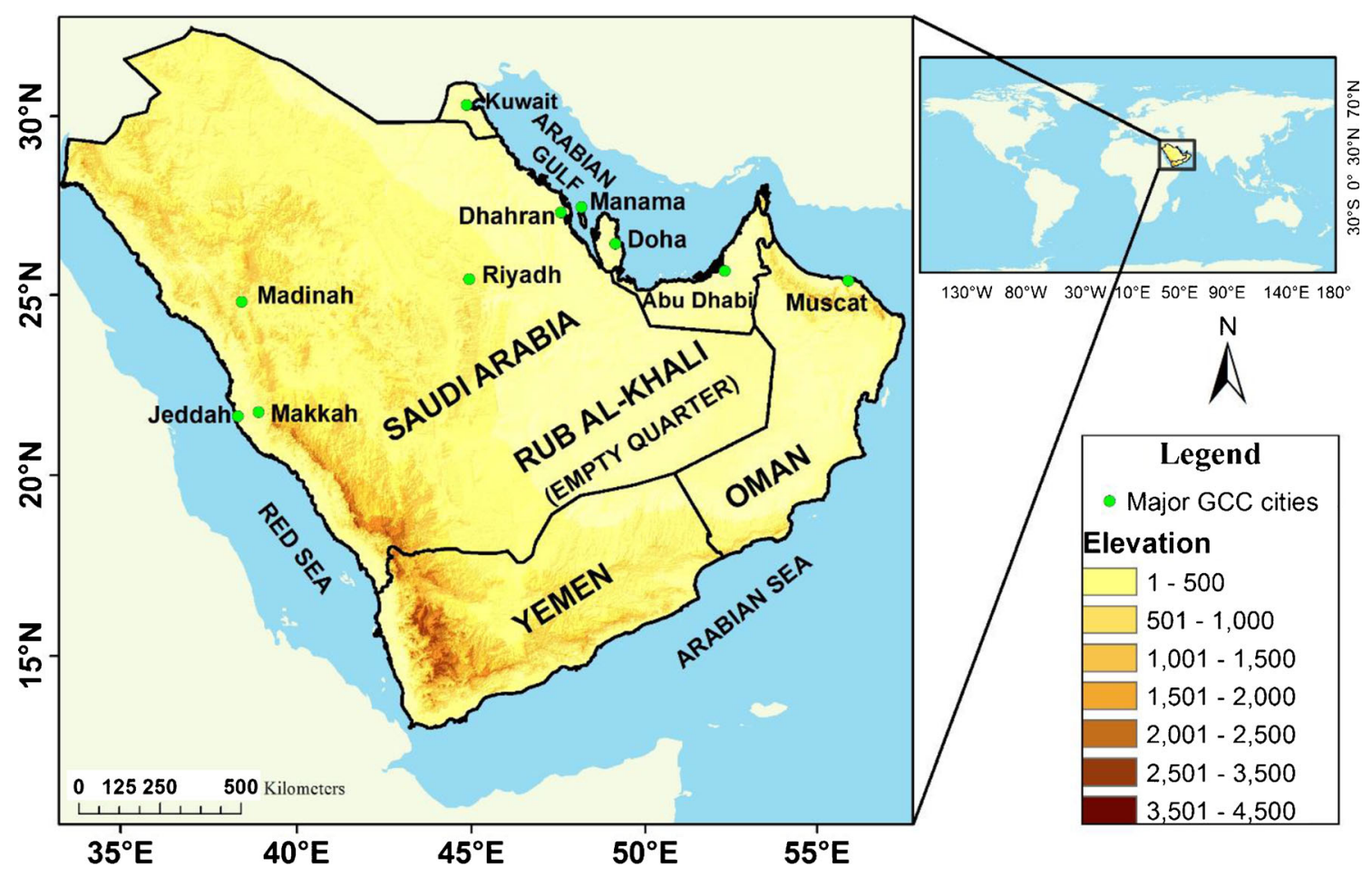

Fig. 1 Arabian Peninsula domain with surface elevation and station locations in ten GCC cities. The green dots indicate the location of six capital cities in the Arabian Gulf states and four societal important cities in Saudi Arabia including Makkah and Madinah

major cities in the GCC states to improve the practical utility of CMIP5 scenarios.

The highest extreme temperature ever reported on the earth is about $60^{\circ} \mathrm{C}$, which is substantially higher than the tolerance level $\left(40^{\circ} \mathrm{C}\right)$ above which the human body tends to fall victim to heat stroke (El-Fadli et al. 2013; Parsons 2006; Glazer 2005). If temperatures were to reach such an extreme level $\left(60{ }^{\circ} \mathrm{C}\right)$, it would not only put the human body in danger but also risk the malfunction of machinery that has been designed for the current climate, such as airplane engines, landing gear, and evaporative cooling systems. The maximum temperature in some interior areas and coastal regions of the Arabian Peninsula has already exceeded $50{ }^{\circ} \mathrm{C}$; a typical example is the recorded $52{ }^{\circ} \mathrm{C}$ temperature in Jeddah on 22 June 2010 (Almazroui et al. 2014). Recently, Kuwait Meteorological Department recorded a peak temperature of $54{ }^{\circ} \mathrm{C}$ at Mitribah on 21 July 2016. This provides supporting evidence for recent studies that highlighted the possibility of large-scale warming over different parts of the Arabian Peninsula in the absence of strong mitigation measures, i.e., the possibility of over $60{ }^{\circ} \mathrm{C}$ in Kuwait, eastern Saudi Arabia, and the United Arab Emirates (Lelieveld et al. 2016; Pal and Eltahir 2016). For such extreme situations, the following question arises: how plausible is it that the maximum temperature over the GCC states will reach $60{ }^{\circ} \mathrm{C}$ by the end of the twenty-first century? If this is genuinely likely, major adaptation and mitigation measures are required to adapt to such high temperature. Another important question is "how reliable are the climate projections for this region?". To address these questions, an analysis of high-resolution and multimodel datasets is required along with present climate observations. Consequently, reasonable estimates of maximum temperatures and related uncertainties are necessary over the GCC states, so that this climate change information can be disseminated to the stakeholders and decision-makers for their longterm planning. In this research, we discuss the past and projected future summer maximum temperatures in the capital city of each GCC state in the Arabian Gulf, along with the two holy cities of Makkah and Madinah as well as Jeddah and Dhahran in the Kingdom of Saudi Arabia, due to their high societal relevance.

Several global climate models (GCMs) and climate system models (CSMs) contributed to the generation of CMIP5 multimodel climate scenarios (Knutson and Ploshay 2016; Meehl et al. 2012; Giorgetta et al. 2013). The horizontal resolutions of GCMs and CSMs are typically quite coarse (Im et al. 2017). The concept and practice of dynamically downscaling GCMs and CSMs using a Regional Climate Model (RCM) are well established for the detailed understanding of climate in a region (Almazroui et al. 2017a, b). In general, downscaled scenarios provide better and more detailed information about the climatic variables (Almazroui et al. 2016a, b). Keeping in mind the importance of climate extremes, the downscaled daily temperatures are also used in the calculation of summer season maximum temperature extremes, 
Fig. 2 Observed (a) annual and (b) summer maximum temperature in the capital cities of each GCC country for the period 1978-2019
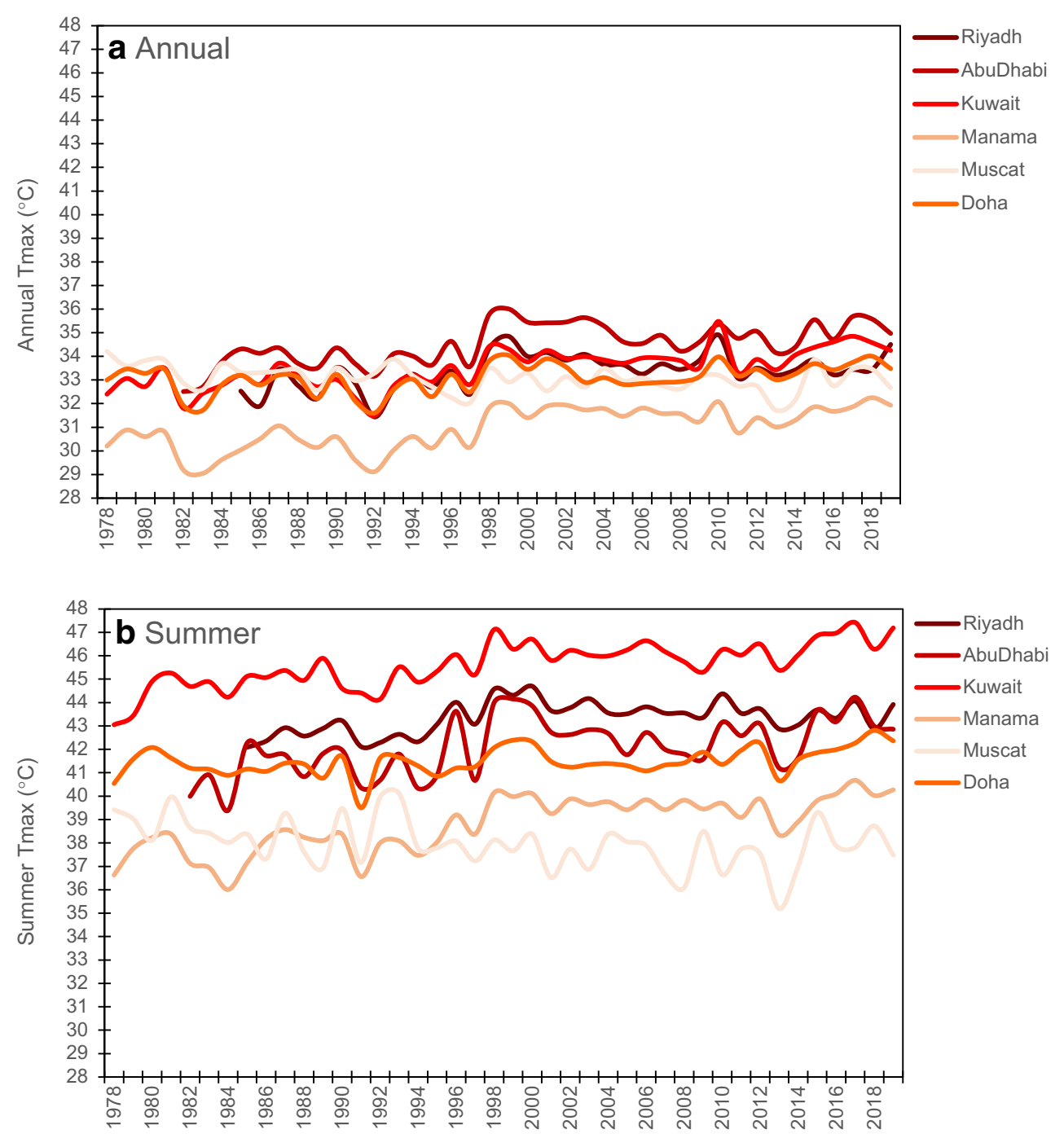

such as warm/cold days for the GCC states in both present and future climates.

Thus, this study aims to downscale the CMIP5 database using RCM over the GCC states and then use the highresolution information to analyze the maximum temperature and SFHT limits for the present as well as future climate during boreal summer. We then investigate the possible increase of average summer maximum temperature to $60{ }^{\circ} \mathrm{C}$

Table 1 Average of annual and summer maximum temperatures trends $\left({ }^{\circ} \mathrm{C}\right.$ decade $\left.{ }^{-1}\right)$ obtained from observed maximum temperature in each GCC capital city for the period 1978-2019. All trends are statistically significant at the $99 \%$ confidence level

\begin{tabular}{lll}
\hline Capital city & Annual & Summer \\
\hline Riyadh & 0.37 & 0.33 \\
Abu Dhabi & 0.50 & 0.62 \\
Kuwait & 0.49 & 0.63 \\
Manama & 0.52 & 0.75 \\
Muscat & -0.17 & -0.36 \\
Doha & 0.21 & 0.21 \\
\hline
\end{tabular}

over different cities of GCC states, and breaches of SFHT limits, in the future climate under the two Representative Concentration Pathways (RCPs), namely RCP4.5 (a mitigation scenario; Thomson et al. 2011) and RCP8.5 (a business-as-usual scenario; Riahi et al. 2011).

\section{Methodology}

In this study, the summer maximum temperature is defined as the average of the monthly maximum temperature for the months from June through August (JJA). Ground-truth values are provided by observational temperatures at stations located throughout the Arabian Gulf states. For simplicity, the temperature at the capital city of each country in the Arabian Gulf states is considered (Fig. 1). In addition, four other important cities, including the holy cities of Makkah and Madinah in the Kingdom of Saudi Arabia, are considered, due to their high societal relevance and because Saudi Arabia covers about 

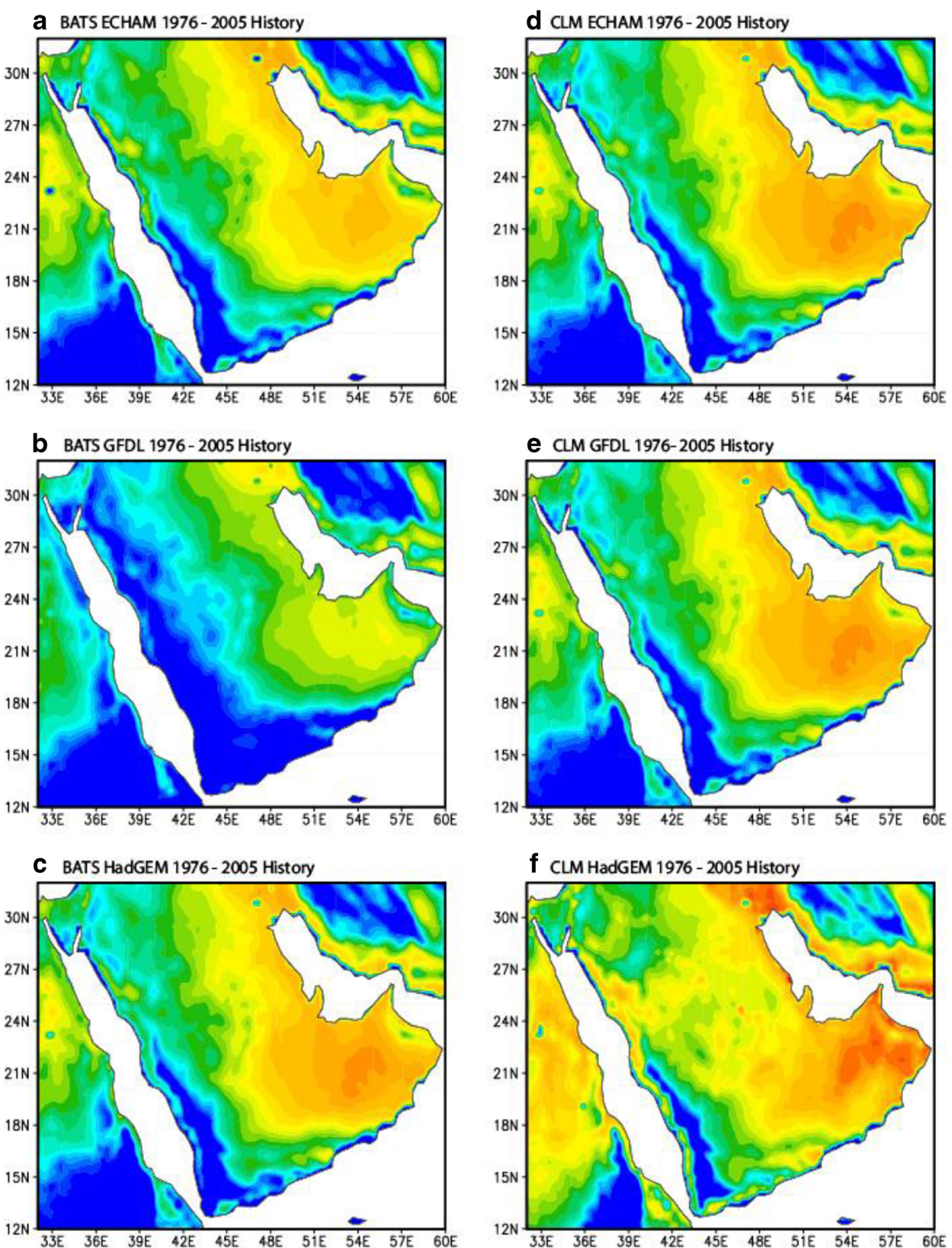

3536373839404142434445464748495051525354555657585960

Fig. 3 The spatial distribution of model simulated summer maximum temperature over the Arabian Peninsula for (a) BATS ECHAM, (b) BATS GFDL, (c) BATS HadGEM, (d) CLM ECHAM, (e) CLM GFDL, and (f) CLM HadGEM, averaged over the period 1976-2005

$80 \%$ of the Peninsula area (Almazroui et al., 2012a, b). Quality control of the daily maximum temperature and management of missing data for the ten surface stations are performed following Almazroui et al. (2013) and corrected 
Fig. 4 The spatial distribution of observed gridded CRU summer maximum temperature over the Arabian Peninsula for the period 1976-2005

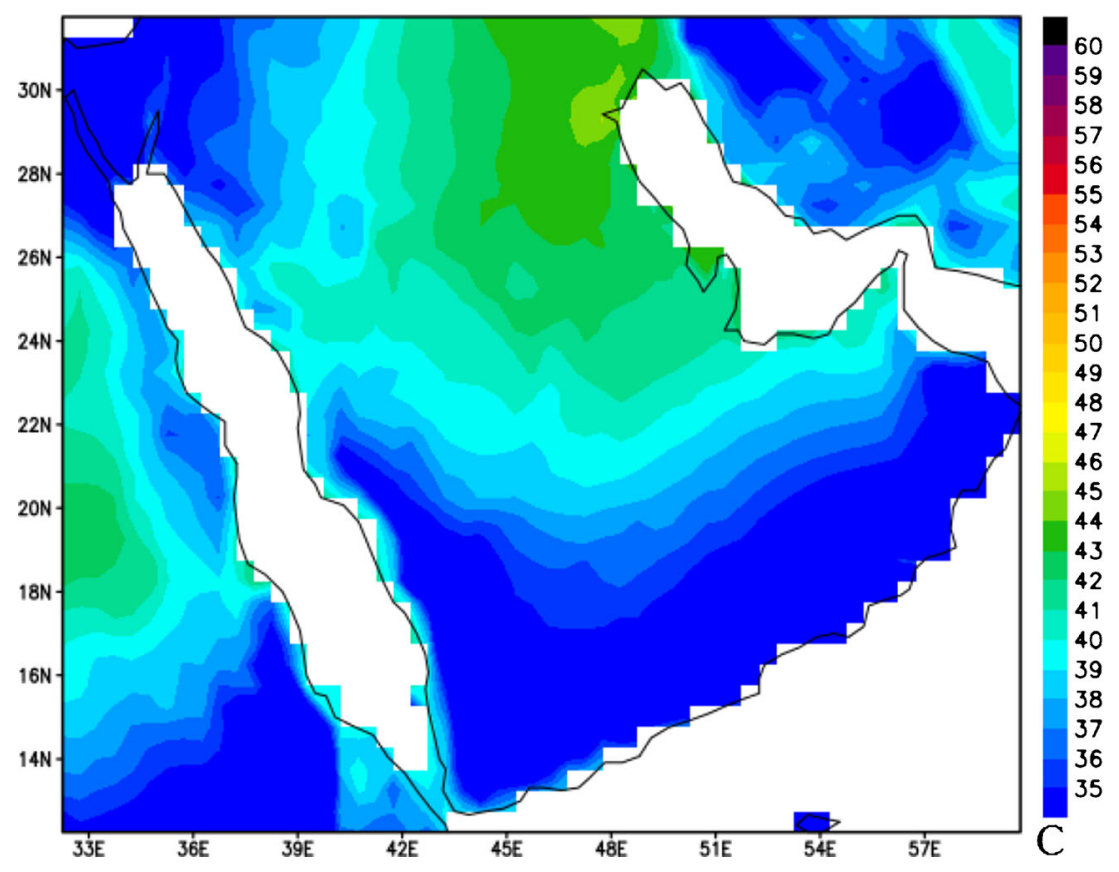

processed at daily and monthly scales. Details of the downscaling of the GCM database using the RCM for the Arabian Peninsula can be found elsewhere (e.g., Almazroui 2011, 2016). The bias (model minus observation) at each station location is calculated for the present climate. The stationbased bias for the current climate is then subtracted from the future scenarios for each model, and the average of this value over all models is referred to as the adjusted temperature. The maximum of maximum temperatures is the highest value of daily maximum temperature (extreme Tmax) at each station. The warming trends are calculated using a simple regression equation. The F-test (Almazroui et al. 2016c) is used to check the statistical significance of the warming trend. A normal quantile plot is used to see the statistical distribution of model simulations and adjusted temperatures. For the calculation of maximum temperature extremes, we used threshold-based and percentile-based extreme indices. The threshold-based hot day metric is calculated using daily maximum temperatures from $\geq 40$ to $\geq 50{ }^{\circ} \mathrm{C}$. The percentile-based indices are warm days (TX90p, maximum temperature $>90$ th percentile), very warm days (TX95p, maximum temperature $>95$ th percentile), extreme warm days (TX99p, maximum temperature $>$ 99th percentile), and cold days (TX10p, maximum temperature $<10$ th percentile), following the procedure recommended by the Expert Team on Climate Change Detection and Indices (ETCCDI, http://iridl.ldeo.columbia.edu/ SOURCES/.WCRP/.CLIVAR/.ETCCDI/). Details of the ETCCDI used for the Arabian Peninsula can be seen in Almazroui et al. (2013), AlSarmi and Washington (2014), Donat et al. (2014), and Islam et al. (2015). This analysis considered only the summer season climate extremes for both present and future climates.

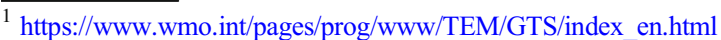



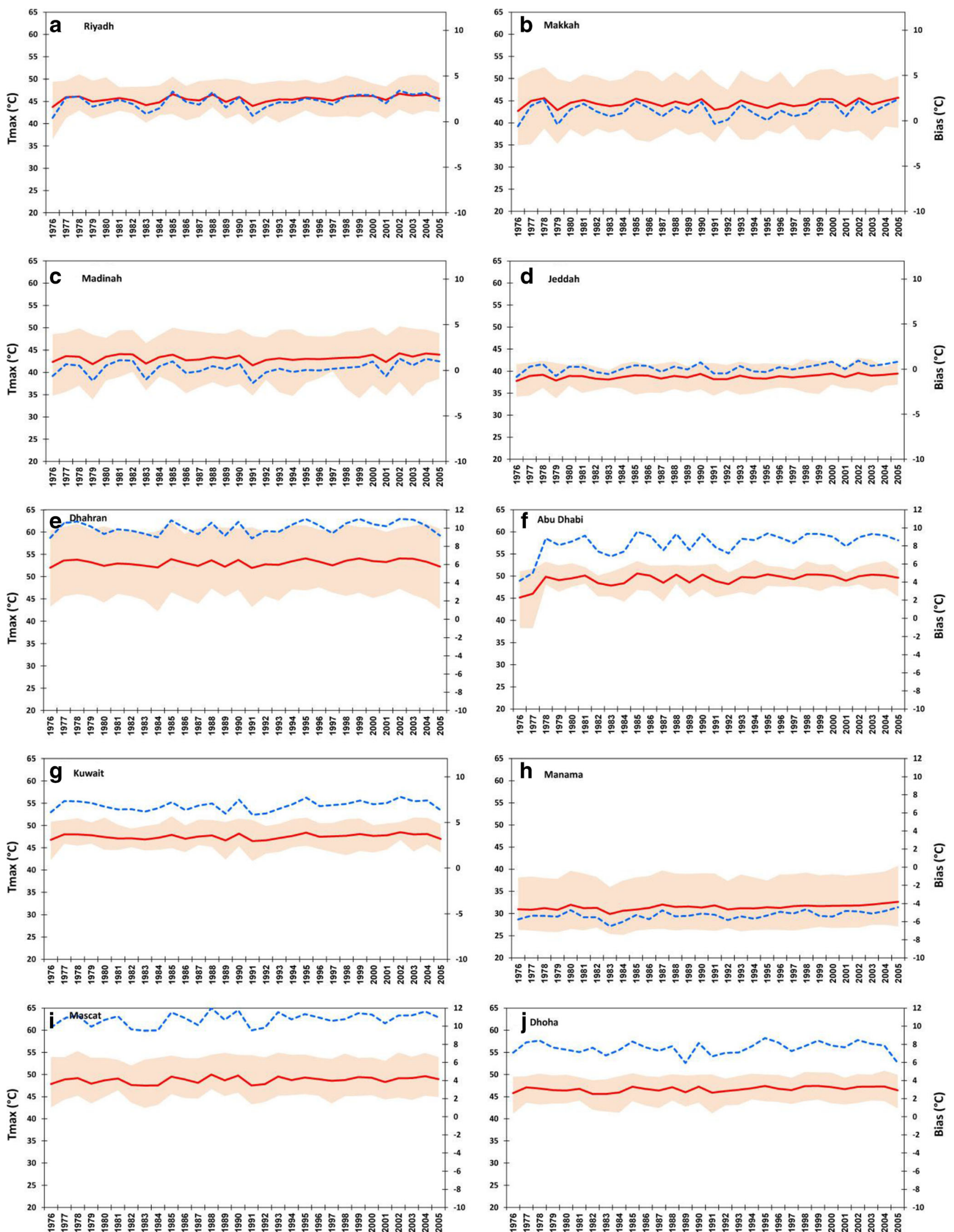
Fig. 5 The evolution of model simulated (average from six simulations) summer maximum temperature (red curves and shading (spread)) and associated bias w.r.t. observation (dashed blue curves) in six capital cities in the GCC states and four major cities across Saudi Arabia during the period 1976-2005. The stations are (a) Riyadh, (b) Makkah, (c) Madinah, (d) Jeddah, (e) Dhahran, (f) Abu Dhabi, (g) Kuwait, (h) Manama, (i) Muscat, and (j) Doha. The primary vertical axis represents

\section{Results and discussion}

\section{Observed maximum temperature climatology at each GCC capital city}

The surface observations averaged over the period 1978 2019 for the six GCC capital cities show that maximum annual mean temperature is within the range of $30.95{ }^{\circ} \mathrm{C}$ (Manama) to $34.53{ }^{\circ} \mathrm{C}$ (Abu Dhabi), while the range is from $37.97{ }^{\circ} \mathrm{C}$ (Muscat) to $45.62{ }^{\circ} \mathrm{C}$ (Kuwait) for the summer season only (Fig. 2a, b). For both annual and summer timescales, the maximum temperature shows an increasing trend for all GCC capital cities except for Muscat, which shows a decreasing trend (Table 1). At the annual scale, the maximum temperature increasing trends for five capital cities are within the range of $0.21-0.52{ }^{\circ} \mathrm{C}$ decade $^{-1}$, while Manama shows the highest $\left(0.52{ }^{\circ} \mathrm{C}\right.$ decade $\left.^{-1}\right)$ and Doha shows the lowest $(0.21$ ${ }^{\circ} \mathrm{C}$ decade $\left.^{-1}\right)$. For the summer season, the increasing trends are within the range of $0.21-0.75{ }^{\circ} \mathrm{C}$ decade $^{-1}$, while Manama shows the highest at $0.75{ }^{\circ} \mathrm{C}$ decade $^{-1}$ and Doha shows the lowest at $0.21{ }^{\circ} \mathrm{C}$ decade ${ }^{-1}$. The rate of decrease of maximum temperature is $-0.17(-0.36){ }^{\circ} \mathrm{C}$ decade $^{-1}$ at Muscat on the annual (summer) scale. All trends are statistically significant at the $99 \%$ confidence level. It is worth mentioning that the proximity of some GCC weather stations near the coast and topography may play an important role in controlling summer maximum temperature.

\section{Simulated summer season maximum temperature climatology}

The model-simulated summer maximum temperatures are generally high in the southeast part of the Arabian Peninsula that extends along the Arabian Gulf coast as far as Kuwait (Fig. 3a-f). Conversely, they are relatively low in the southwest hilly areas. RegCM4 with CLM simulates lower temperature over the central Peninsula than it does with BATS, except for the Red Sea coast. There is a large variation in the maximum temperature climatology (1976-2005), ranging from below $35{ }^{\circ} \mathrm{C}$ to as high as $55^{\circ} \mathrm{C}$ in different parts of the Peninsula. Our concern is how reliable these simulations are, given that there are differences among the models and land surface schemes within RegCM4 and that the climate model simulations are not free from uncertainties. The overall pattern of simulated temperatures is similar to gridded observations from the climatic research unit (CRU, http:// www.cru.uea.ac.uk) data (Fig. 4), in particular for GFDL with BATS, although that simulation shows very high temperature in the southeast of the Peninsula. The CRU data shows that summer maximum temperatures are high in the eastern and northeast regions of the Peninsula, while low in the south, southwest, and northwest regions (Fig. 4). The observed maximum temperature ranges from $35^{\circ} \mathrm{C}$ to $45^{\circ} \mathrm{C}$. Even though the gridded CRU data are based on a low density station network over the region, the RegCM simulations overestimate temperature for the southeast region, as reported by Almazroui et al. (2016a, b). The reliability of the model simulations in comparison with the meteorological surface observations has not been addressed in earlier studies (e.g., Pal and

Table 2 Observed and simulated model average maximum temperature over three GCC cities for the period 1978-2005. The three selected cities are Jeddah, Kuwait, and Manama showing nominal difference, overestimation, and underestimation, respectively

\begin{tabular}{|c|c|c|c|c|c|c|}
\hline \multirow[t]{2}{*}{ Year } & \multicolumn{2}{|l|}{ Jeddah } & \multicolumn{2}{|l|}{ Kuwait } & \multicolumn{2}{|l|}{ Manama } \\
\hline & Observation & Model & Observation & Model & Observation & Model \\
\hline 1978 & 37.7 & 39.2 & 43.0 & 48.0 & 36.6 & 31.2 \\
\hline 1979 & 37.9 & 37.9 & 43.4 & 47.8 & 37.7 & 30.8 \\
\hline 1980 & 37.3 & 38.9 & 44.9 & 47.4 & 38.2 & 32.0 \\
\hline 1981 & 37.8 & 38.9 & 45.3 & 47.1 & 38.4 & 31.2 \\
\hline 1982 & 38.7 & 38.3 & 44.7 & 47.1 & 37.1 & 31.3 \\
\hline 1983 & 38.4 & 38.1 & 44.9 & 46.9 & 36.9 & 29.9 \\
\hline 1984 & 37.4 & 38.7 & 44.2 & 47.2 & 36.0 & 30.6 \\
\hline 1985 & 37.9 & 39.1 & 45.1 & 47.9 & 37.2 & 30.9 \\
\hline 1986 & 38.5 & 39.0 & 45.1 & 47.0 & 38.2 & 31.3 \\
\hline 1987 & 38.6 & 38.3 & 45.4 & 47.5 & 38.6 & 32.1 \\
\hline 1988 & 39.2 & 38.9 & 45.0 & 47.8 & 38.2 & 31.5 \\
\hline 1989 & 37.9 & 38.6 & 45.9 & 46.6 & 38.1 & 31.6 \\
\hline 1990 & 37.8 & 39.4 & 45.1 & 48.2 & 38.4 & 31.4 \\
\hline 1991 & 37.2 & 38.2 & 45.0 & 46.5 & 36.6 & 31.8 \\
\hline 1992 & 37.9 & 38.2 & 44.1 & 46.7 & 38.0 & 30.9 \\
\hline 1993 & 37.9 & 39.0 & 45.5 & 47.2 & 38.1 & 31.2 \\
\hline 1994 & 38.8 & 38.4 & 44.9 & 47.7 & 37.5 & 31.2 \\
\hline 1995 & 39.1 & 38.3 & 45.3 & 48.4 & 38.0 & 31.4 \\
\hline 1996 & 38.1 & 38.9 & 46.1 & 47.5 & 39.2 & 31.3 \\
\hline 1997 & 39.6 & 38.6 & 45.2 & 47.6 & 38.4 & 31.7 \\
\hline 1998 & 39.4 & 38.9 & 47.1 & 47.7 & 40.2 & 31.8 \\
\hline 1999 & 38.8 & 39.1 & 46.3 & 48.1 & 40.0 & 31.7 \\
\hline 2000 & 38.8 & 39.5 & 46.7 & 47.7 & 40.1 & 31.7 \\
\hline 2001 & 39.6 & 38.7 & 45.8 & 47.8 & 39.3 & 31.8 \\
\hline 2002 & 39.4 & 39.6 & 46.1 & 48.5 & 39.9 & 31.8 \\
\hline 2003 & 39.6 & 39.0 & 46.0 & 48.0 & 39.6 & 32.0 \\
\hline 2004 & 38.6 & 39.2 & 46.0 & 48.1 & 39.8 & 32.4 \\
\hline 2005 & 39.4 & 39.5 & 46.3 & 47.0 & 39.4 & 32.7 \\
\hline
\end{tabular}


a BATS ECHAM 2070-2099 RCP4.5

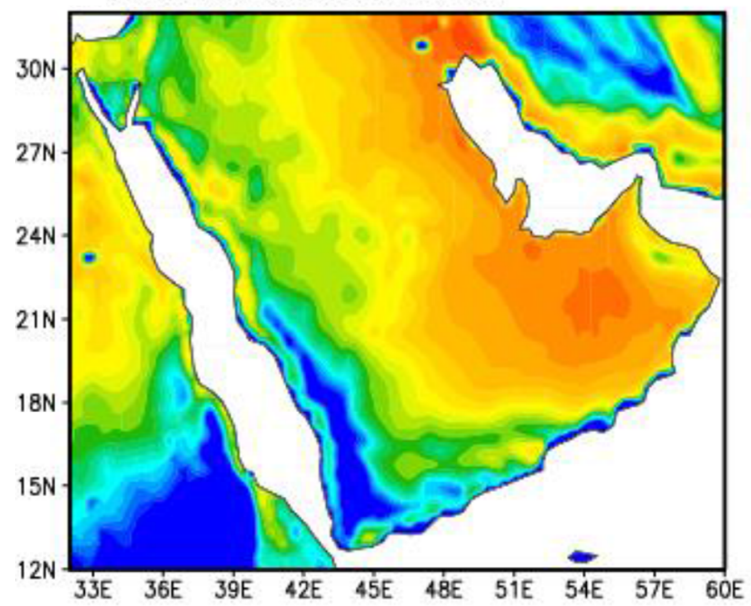

b BATS GFDL 2070-2099 RCP4.5

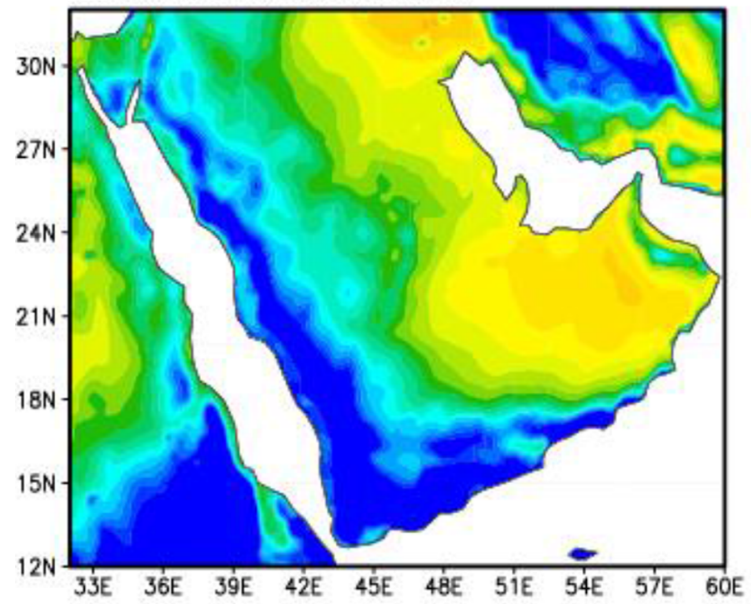

\section{BATS HadGEM 2070-2099 RCP4.5}

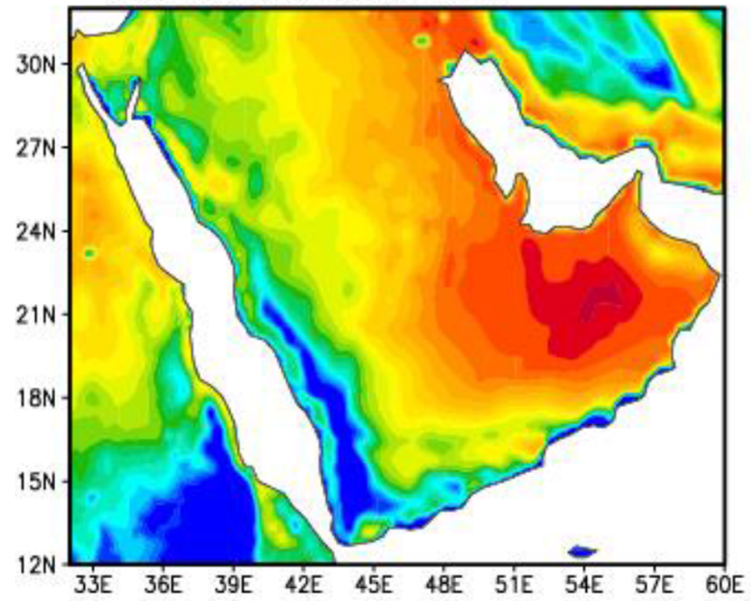

d CLM ECHAM 2070-2099 RCP45

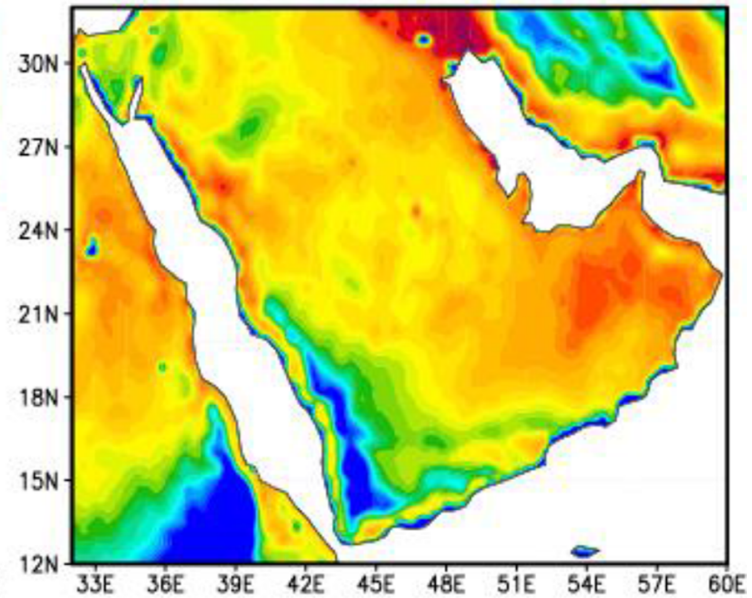

e CLM GFDL 2070-2099 RCP45

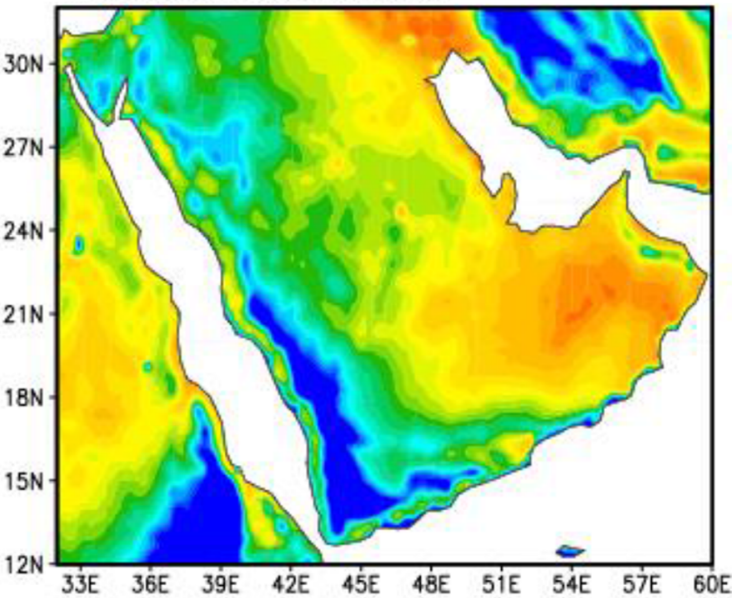

f CLM HadGEM 2070-2099 RCP4.5

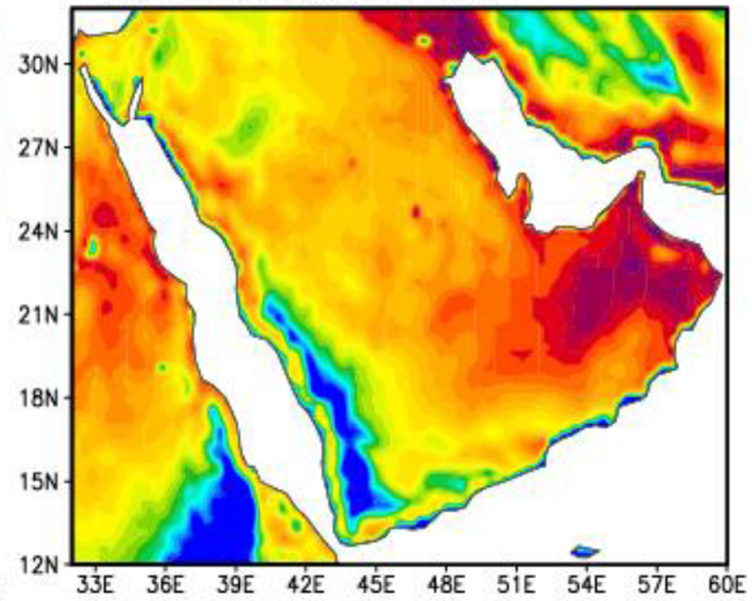

3536373839404142434445464748495051525354555657585960

Fig. 6 The spatial distribution of model simulated summer maximum temperature over the Arabian Peninsula under RCP4.5 for (a) BATS ECHAM, (b) BATS GFDL, (c) BATS HadGEM, (d) CLM ECHAM, (e) CLM GFDL, and (f) CLM HadGEM, averaged over the period 2070-2099 
a BATS ECHAM 2070 - 2099 RCP8.5

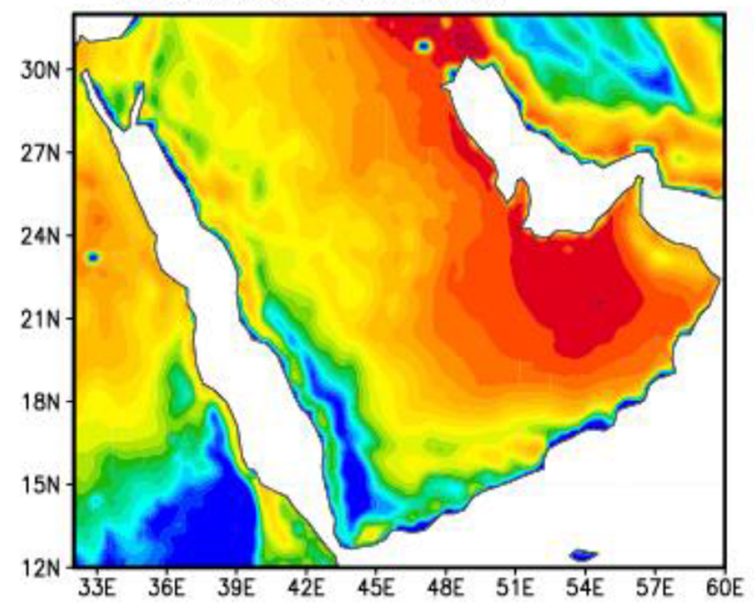

b BATS GFDL 2070 - 2099 RCP8.5

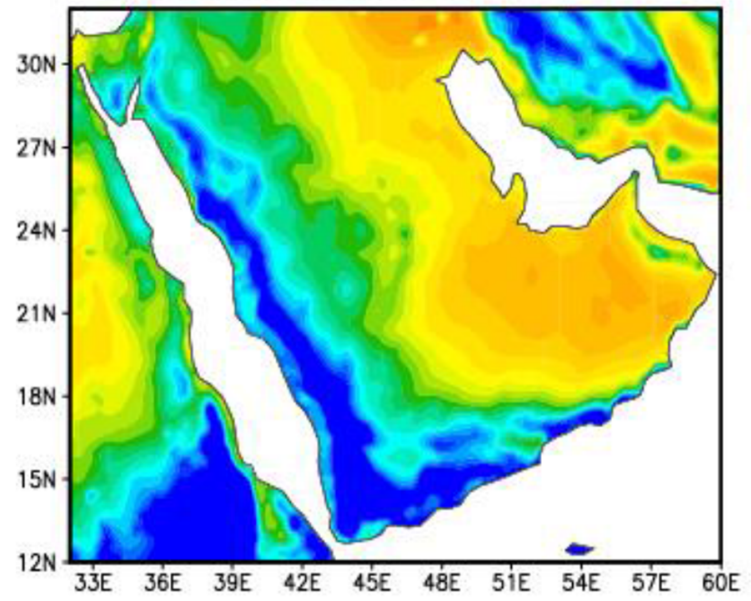

C BATS HadGEM 2070-2099 RCP8.5

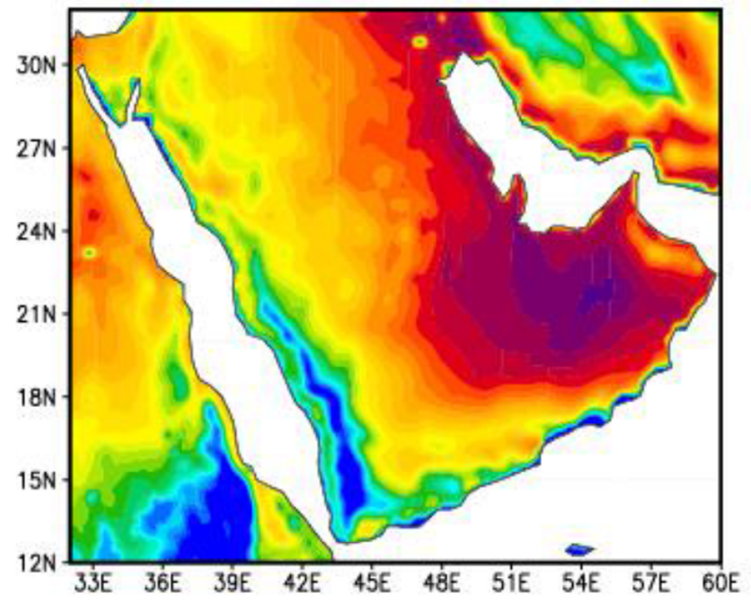

\section{d CLM ECHAM 2070-2099 RCP8.5}

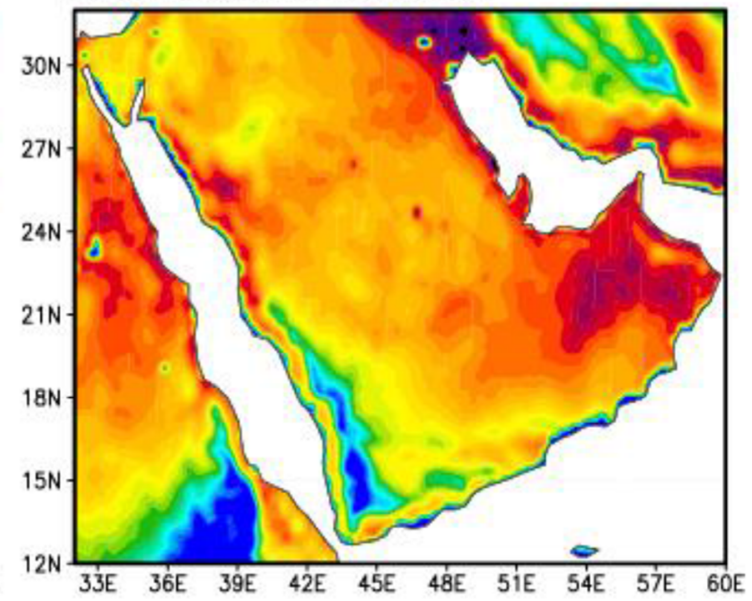

e CLM GFDL 2070-2099 RCP8.5

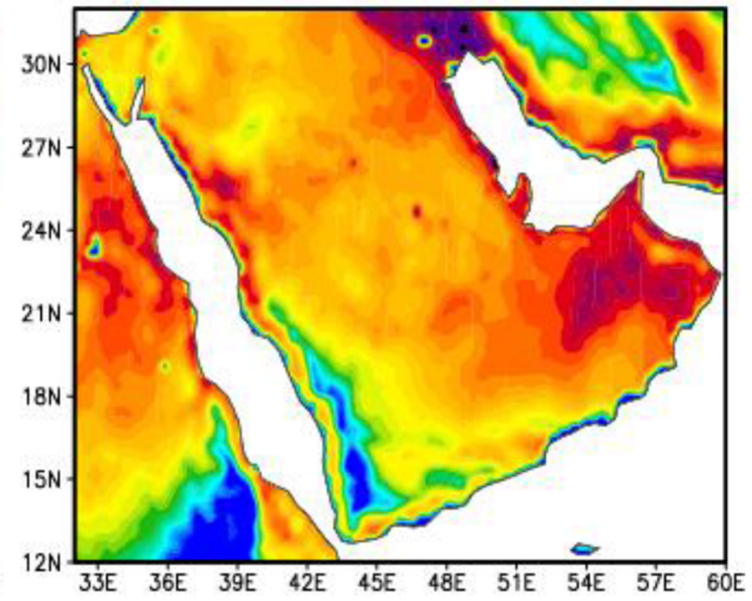

f CLM HadGEM 2070-2099 RCP8.5

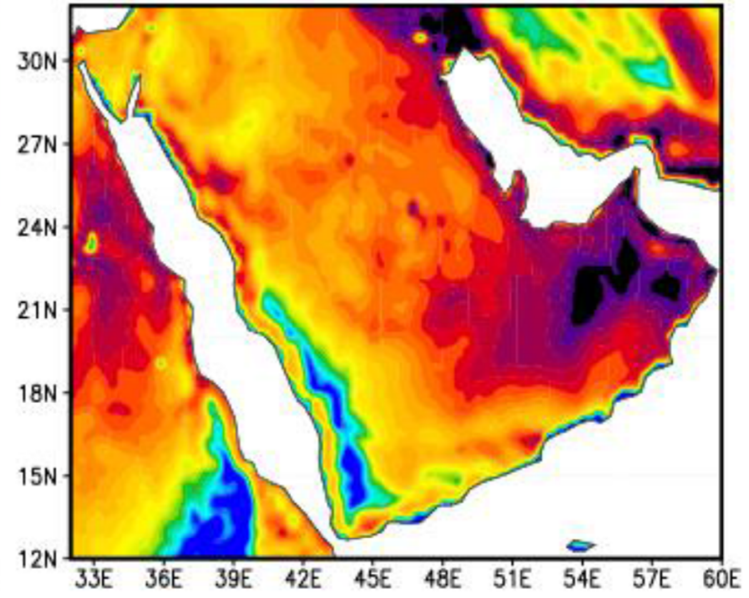

3536373839404142434445464748495051525354555657585960

Fig. 7 The spatial distribution of model simulated summer maximum temperature over the Arabian Peninsula under RCP8.5 for (a) BATS ECHAM, (b) BATS GFDL, (c) BATS HadGEM, (d) CLM ECHAM, (e) CLM GFDL, and (f) CLM HadGEM, averaged over the period 2070-2099 

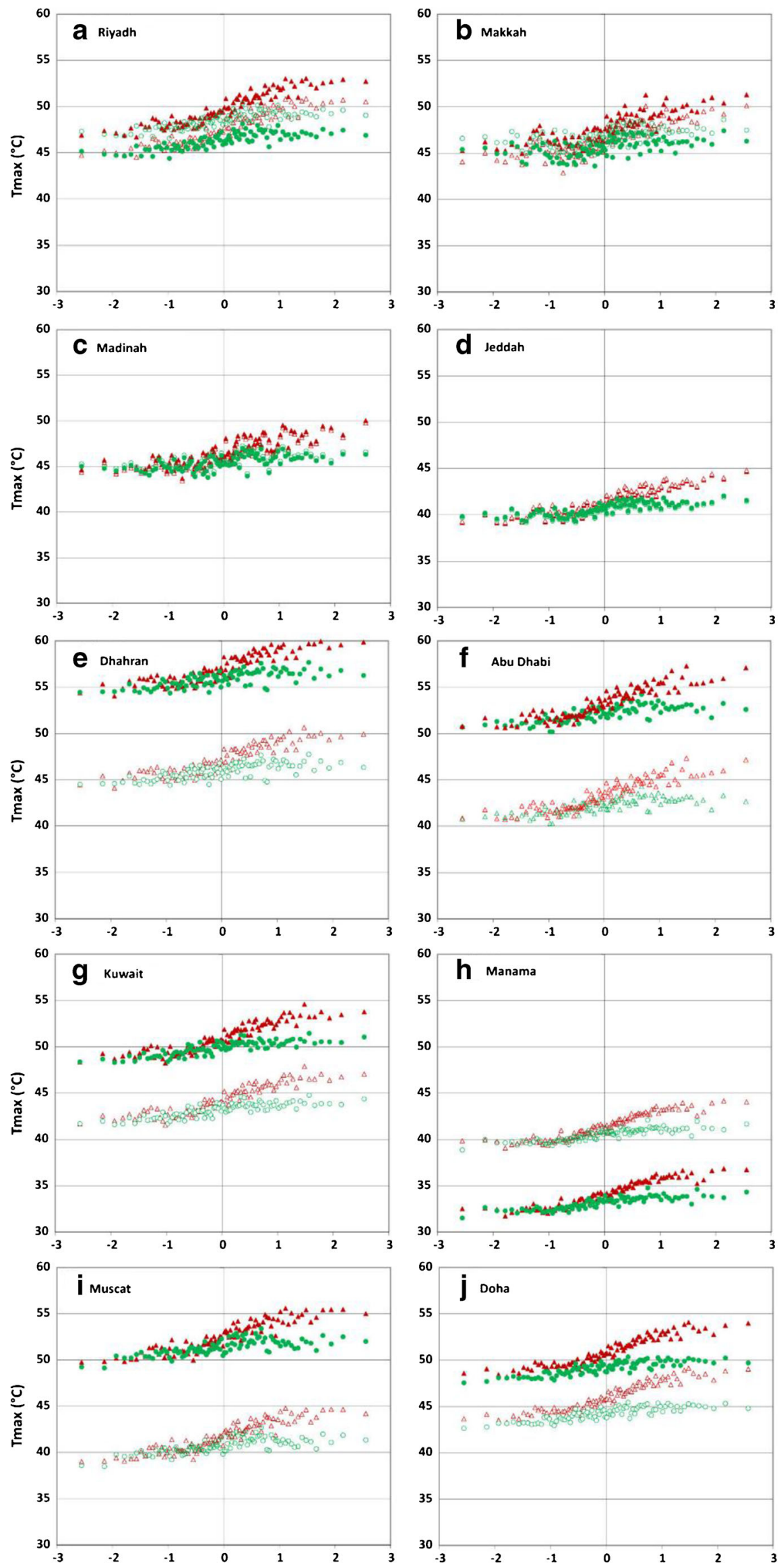
Fig. 8 Normal quantile plot using mean and standard deviation for model simulated (closed triangles and circules, averaged from six simulations) summer maximum temperature with adjusted (open triangles and circules, model minus bias) at six capital cities of GCC states and four major cities over Saudi Arabia under RCP4.5 (green) and RCP8.5 (red) scenarios for the projection period 2006-2099. The stations are (a)

Eltahir 2016). Therefore, for better insight into the temperature over the GCC states, a number of meteorological surface
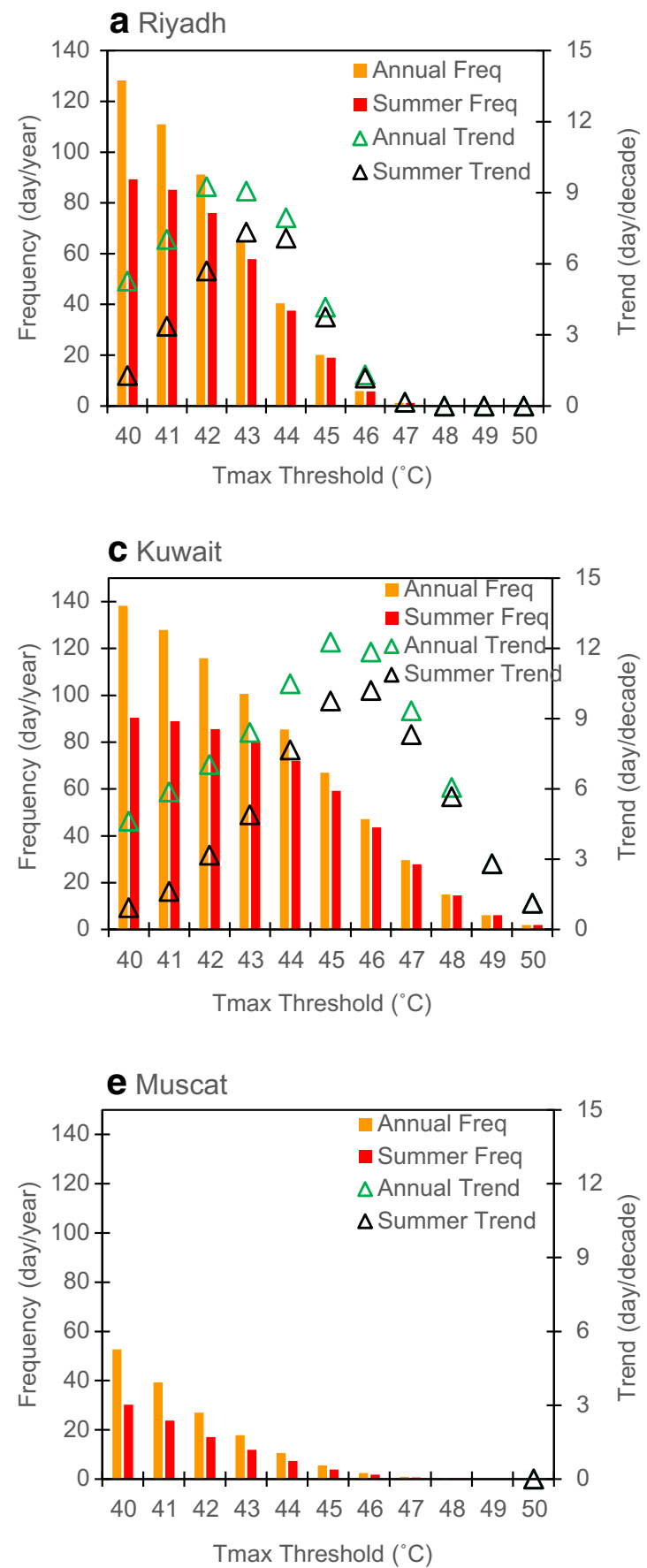

Fig. 9 Frequency $\left(\right.$ days year $\left.{ }^{-1}\right)$ and trend (days decade ${ }^{-1}$ ) of hot days above a maximum temperature threshold at six GCC capital cities obtained from the surface observations

station locations are selected where both simulated and observed data are compared, as shown in Fig. 5. The model simulation data are extracted at meteorological surface station locations following Islam (2009) and Islam and Uyeda (2007). In this procedure, the nearest grid point value within $25 \mathrm{~km}$ from the surface station location is used to provide the simulated data for a particular station. For a detailed understanding of the difference between model simulations and surface observations, summer maximum temperature for three stations
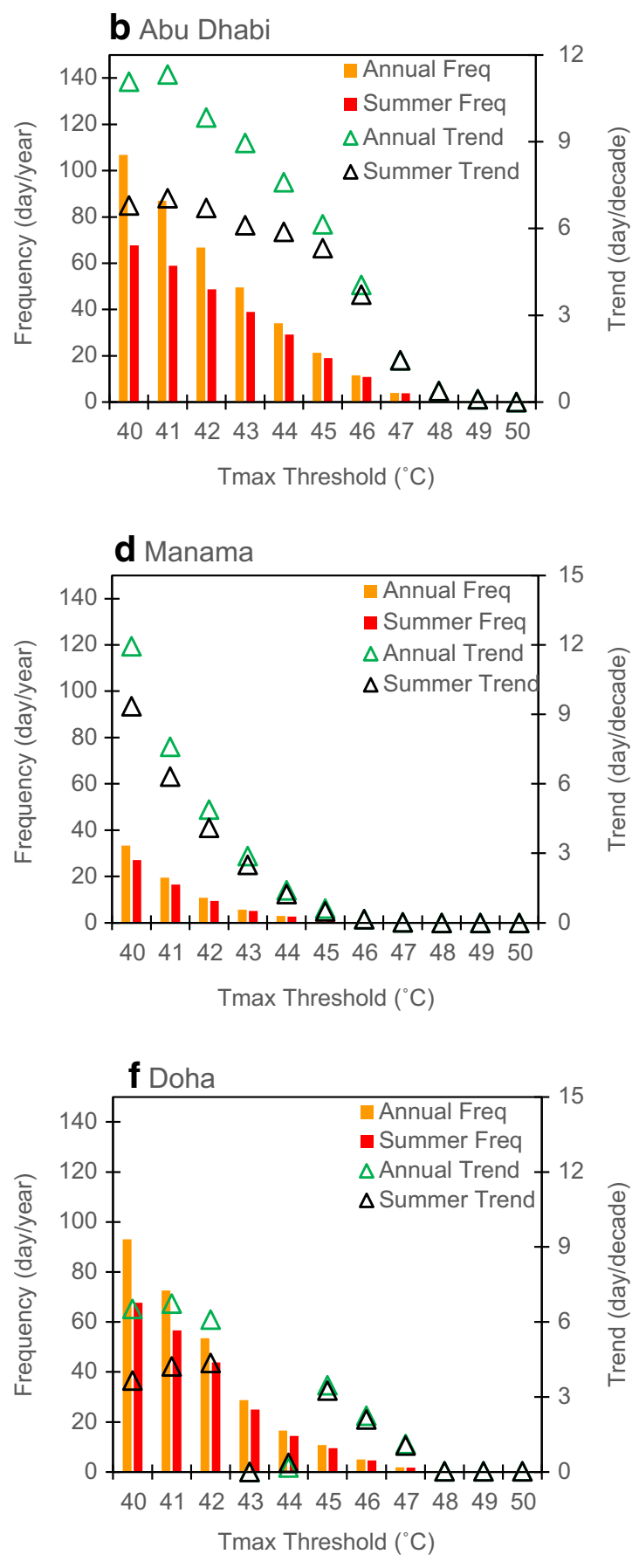

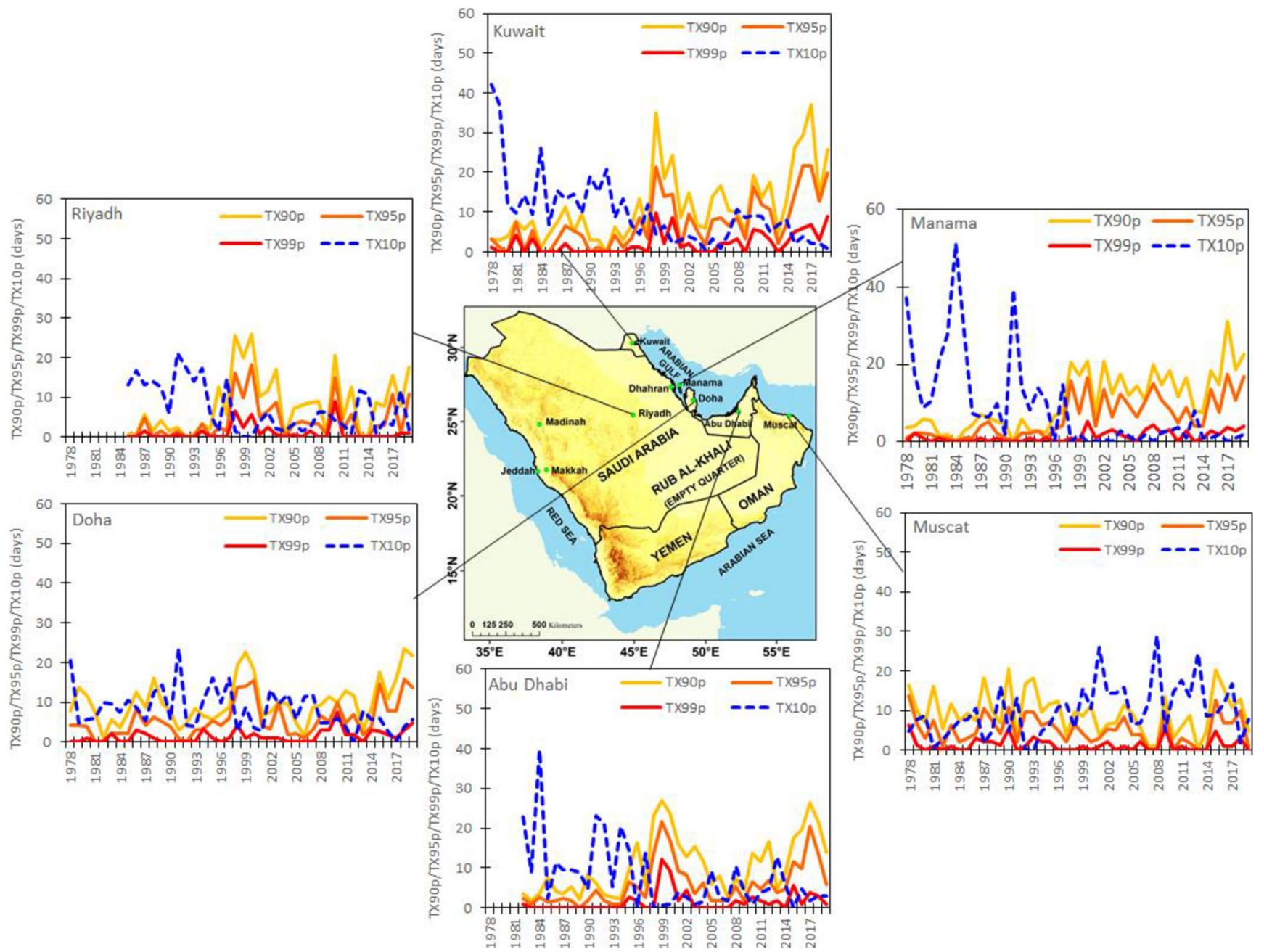

Fig. 10 Warm days (TX90p), very warm days (TX95p), extreme warm days (TX99p), and cold days (TX10p) obtained from surface observations at GCC capital cities for the present climate 1978-2019

obtained from both model and observations is presented in Table 2. Jeddah is representative of those stations where model simulations have only a nominal difference from observations in most years; both data and observations are very similar. The Kuwait station is representative of those where model overestimated the observed temperatures every year, while the Manama station is one where model underestimated the recorded temperatures every year (Table 2 ).

As shown in Fig. 5, the model simulations of temperature for Riyadh, Kuwait, Abu Dhabi, Muscat, and Doha show warm bias (overestimation) among the six capital cities of the GCC states, while at Manama the simulations shows cold bias (underestimation). Among the other four important cities of Saudi Arabia, only a nominal bias is found for Makkah, Madinah, and Jeddah, while there is a large positive bias for Dhahran. The temperature bias exceeds $10{ }^{\circ} \mathrm{C}$ for Muscat and Dhahran, while it surpasses $7{ }^{\circ} \mathrm{C}$ for Kuwait and Doha in some years. This indicates that the model simulations have both warm and cold biases that are location dependent. At some stations, the simulated values are too large while other locations they are too small. The over- and underestimation of model output still need more investigation. The model-

Table 3 Warm days and cold days trends (days decade ${ }^{-1}$ ) obtained from observed and simulated summer maximum temperature in each GCC capital city for the current period 1978-2019. The bold font indicates significant trends at the $90 \%$ level, while the asterisk sign (*) indicates significant trends at the $95 \%$ level and double asterisk sign indicates significant trends at the $99 \%$ level.

\begin{tabular}{|c|c|c|c|c|}
\hline & \multicolumn{2}{|c|}{ Warm days (TX90p) } & \multicolumn{2}{|c|}{ Cold days (TX10p) } \\
\hline & Observation & Model & Observation & Model \\
\hline Riyadh & 2.21 & $7.99 * *$ & $-3.22 * *$ & $-2.64 * *$ \\
\hline Abu Dhabi & $3.46^{* *}$ & $8.47 * *$ & $-3.90 * *$ & $-2.07 * *$ \\
\hline Kuwait & $4.37 * *$ & $8.47 * *$ & $-4.83 * *$ & $-2.80 * *$ \\
\hline Manama & $4.54 * *$ & $5.71 * *$ & $-6.25^{* *}$ & $-3.52^{*}$ \\
\hline Muscat & -0.94 & $5.14 * *$ & $2.22 * *$ & $-1.67 *$ \\
\hline Doha & $1.58^{*}$ & $7.59 * *$ & $-1.62 * *$ & $-2.50 * *$ \\
\hline
\end{tabular}


simulated data for the historical period 1978-2005 indicates that the trend follows the observations for all cities except for Muscat, which shows negative trend. Since the biases (especially the larger ones) appear to be systematic rather than random, we have to consider each location individually. Uncertainty in the simulations is larger for some cities than for others, which can be seen from the range among the models (Fig. 5). Therefore, some temperature adjustment is required based on the location-specific biases. This is a very important and urgent matter for application-oriented projects in the region.

\section{Summer maximum temperature projection}

Model projections indicate that the average summer maximum temperatures over the last three decades of the twentyfirst century will be much higher than the present climate and in particular will be very high in the eastern areas of the Peninsula (Figs. 6a-f and 7). The average summer maximum temperature could exceed $60^{\circ} \mathrm{C}$ in some quarters within the
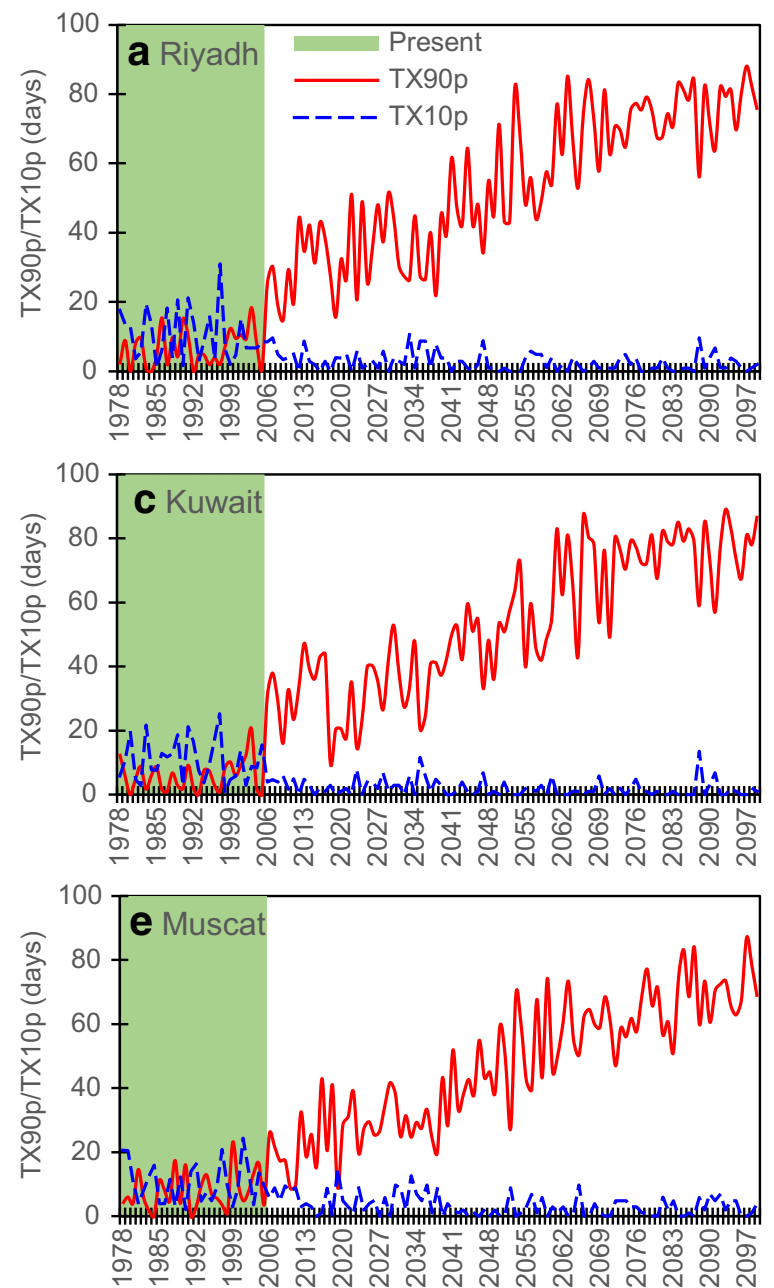

Peninsula under RCP8.5 (Fig. 7). Similarly, by the end of the twenty-first century, the average summer maximum temperature could exceed $55^{\circ} \mathrm{C}$ in the Arabian Gulf coast regions. As mentioned above, the model-simulated temperatures show large biases, both positive and negative, as compared with the observations for the present climate. Therefore, we suspect that these biases also persist in the projected temperature. We understand that the bias in the future climate may not necessarily follow the same pattern as it does in the present climate. However, to understand the likelihood of real temperature rise in the far future period of 2070-2099, the simulated temperature in the six capital cities of the GCC states and four major cities in Saudi Arabia are shown along with the adjusted temperature (model minus base period bias), in Fig. 8. In some cities (e.g., Dhahran, Kuwait, Abu Dhabi, Muscat, Doha), the adjusted projected temperature is much lower than the model simulations, while for Makkah, Madinah, and Jeddah, the adjustments to the simulated temperature are much smaller. The adjusted projected temperature over Manama is much higher than those obtained from model simulations. There is a clear
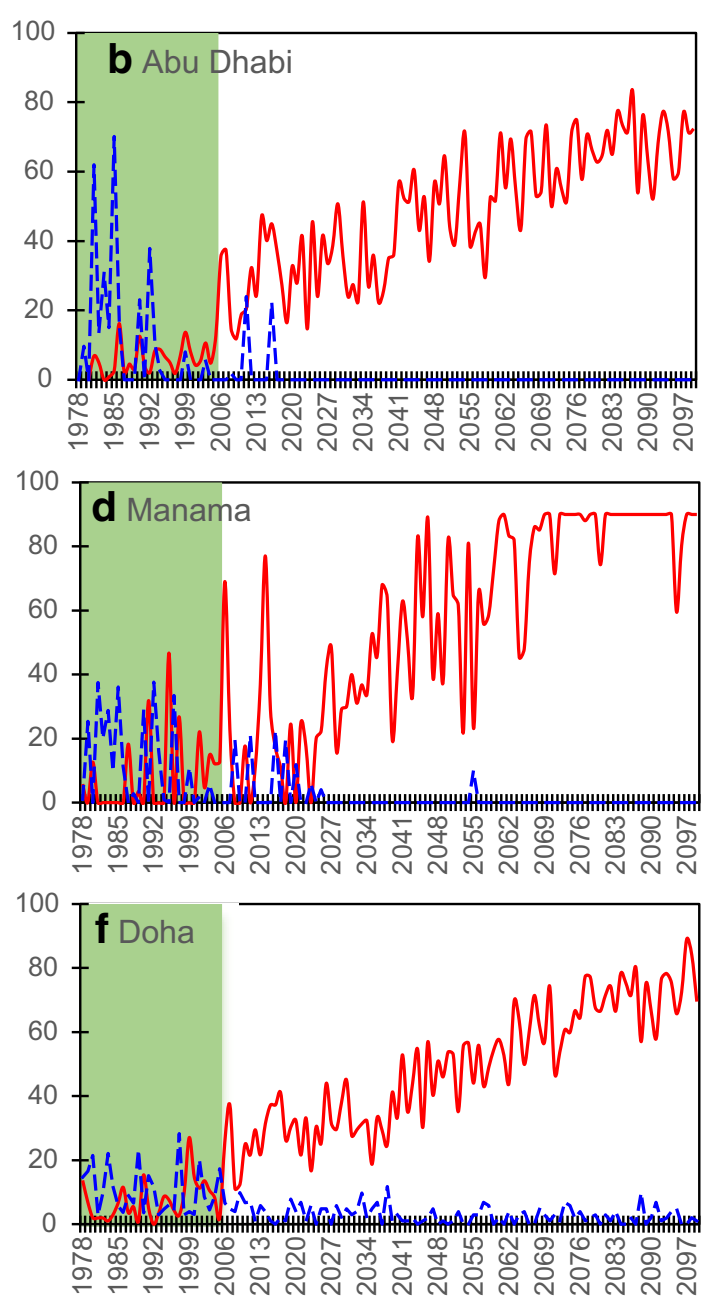

Fig. 11 Warm days (TX90p) and cold days (TX10p) obtained from RegCM4 simulations under RCP8.5 at GCC capital cities in the present and future climates. The green shade indicates the present climate 

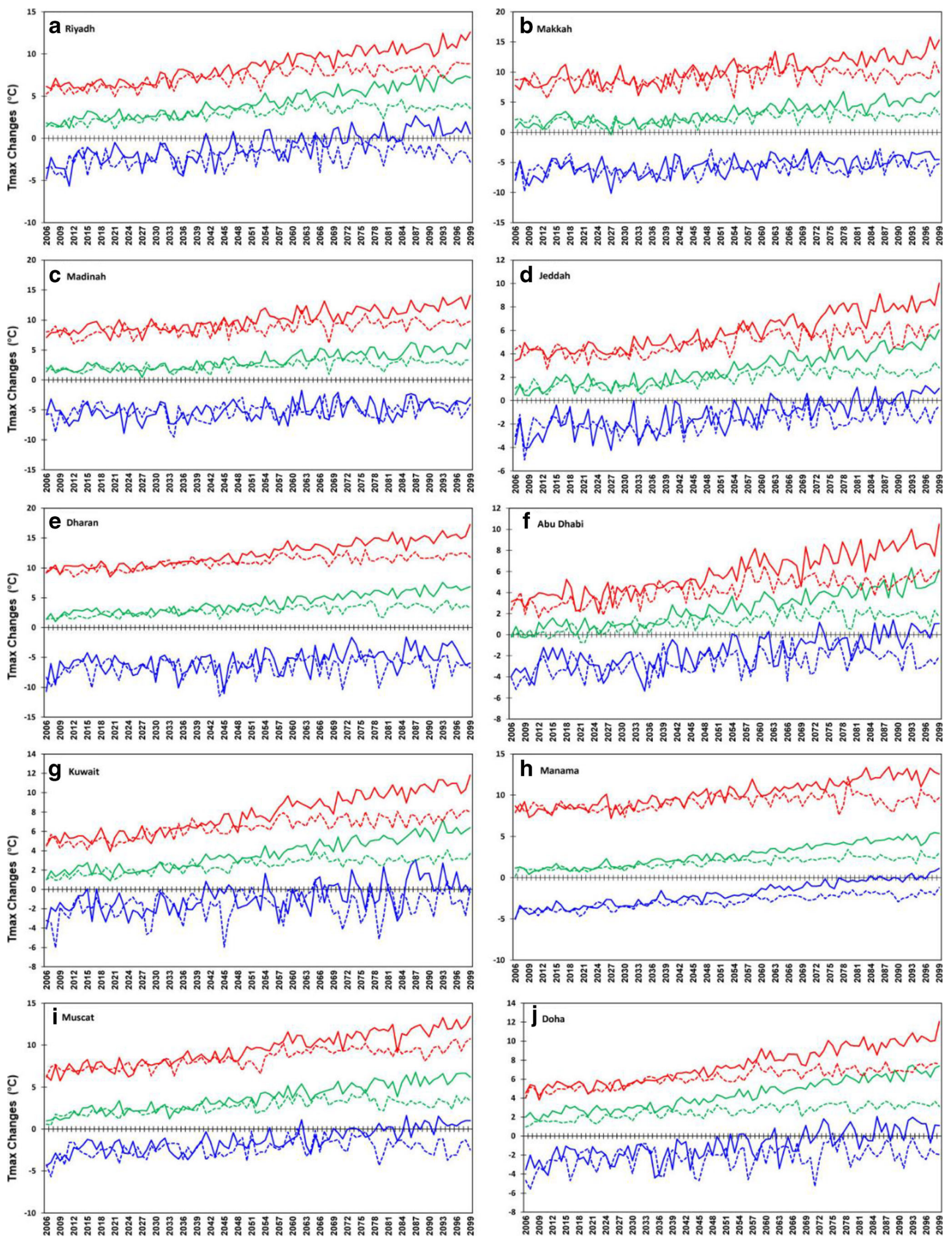
Fig. 12 The evolution of the changes in adjusted (model minus bias) average summer maximum temperature (green lines) with uncertainties (blue lines for lower limit and red lines for upper limit) at six capital cities of GCC states and four major cities in Saudi Arabia under RCP4.5 (dashed lines) and RCP8.5 (solid lines) scenarios for the projection period 20062099. The stations are (a) Riyadh, (b) Makkah, (c) Madinah, (d) Jeddah, (e) Dhahran, (f) Abu Dhabi, (g) Kuwait, (h) Manama, (i) Muscat, and (j)

indication that the model seems to overestimate temperature by about $8-10{ }^{\circ} \mathrm{C}$ for Dhahran, Abu Dhabi, Muscat, and Kuwait. Similarly, underestimation for Manama is about 7-8 ${ }^{\circ} \mathrm{C}$. Figure 8 also shows that both model and adjusted data do not come perfectly from a standard normal distribution because some of them do not fall neatly along a straight line. For lower values of average summer maximum temperatures, model simulations are in line with adjusted temperature. However, for higher values, i.e., at the end of the twentyfirst century, there is a big difference between the simulated and adjusted temperatures.

Considering the dry-bulb temperature SFHT of $42{ }^{\circ} \mathrm{C}$ over the region, the adjusted projected temperature will exceed the SFHT limit for all cities except Manama under RCP4.5 (Fig. $8)$. In the case of the RCP8.5 scenario, the average summer maximum temperature will cross the SFHT limit in all cities. Figure 8 also indicates that the adjusted average summer maximum temperature will not reach $50{ }^{\circ} \mathrm{C}$ by the end of the twenty-first century except for Dhahran, Makkah, and Riyadh, which is projected at $51^{\circ} \mathrm{C}$. However, daily extremes may have different characteristics, as discussed in "Changes in summer maximum temperature in the twenty-first century" section.

Table 4 Adjusted average summer maximum temperature increase rate $\left({ }^{\circ} \mathrm{C}\right.$ decade $\left.{ }^{-1}\right)$ in each GCC city for the lower, higher, and ensemble mean under RCP4.5 and RCP8.5 for the future period 2020-2099. The asterisk sign (*) indicates significant trends at the $95 \%$ level and double asterisk sign indicates significant trends at the $99 \%$ level

\begin{tabular}{|c|c|c|c|c|c|c|}
\hline \multirow[t]{2}{*}{ City } & \multicolumn{3}{|l|}{$\mathrm{RCP} 4.5$} & \multicolumn{3}{|l|}{$\mathrm{RCP} 8.5$} \\
\hline & Lower & Higher & Ensemble & Lower & Higher & Ensemble \\
\hline Riyadh & $0.17 * *$ & $0.31 * *$ & $0.23 * *$ & $0.52 * *$ & $0.69 * *$ & $0.66^{* *}$ \\
\hline Makkah & $0.20 * *$ & $0.26^{* *}$ & $0.27 * *$ & $0.36^{* *}$ & $0.70 * *$ & $0.63 * *$ \\
\hline Madinah & $0.17 * *$ & $0.22 * *$ & $0.19 * *$ & $0.27 * *$ & $0.61 * *$ & $0.52 * *$ \\
\hline Jeddah & $0.21 * *$ & $0.30^{* *}$ & $0.22 * *$ & $0.42 * *$ & $0.61 * *$ & $0.53 * *$ \\
\hline Dhahran & 0.11 & $0.28 * *$ & $0.20 * *$ & $0.37 * *$ & $0.78 * *$ & $0.62 * *$ \\
\hline Abu Dhabi & $0.17 * *$ & $0.35^{* *}$ & $0.22 * *$ & $0.48 * *$ & $0.75 * *$ & $0.63 * *$ \\
\hline Kuwait & 0.09 & $0.30 * *$ & $0.20 * *$ & $0.36^{* *}$ & $0.77 * *$ & $0.60 * *$ \\
\hline Manama & 0.17 & 0.13 & 0.16 & $0.45 * *$ & $0.51 * *$ & $0.49 * *$ \\
\hline Muscat & $0.10 *$ & $0.35 * *$ & $0.19 * *$ & $0.46^{* *}$ & $0.71 * *$ & $0.58 * *$ \\
\hline Doha & $0.13 *$ & $0.28 * *$ & $0.20 * *$ & $0.30 * *$ & $0.75 * *$ & $0.58 * *$ \\
\hline
\end{tabular}

Warm extremes in the present and future period

Threshold-based hot days' frequency is high in Kuwait, Abu Dhabi, and Riyadh while low in Manama and Muscat (Fig. 9). The number of annual hot days with maximum temperature $\geq 40{ }^{\circ} \mathrm{C}$ is observed to be 138 days for Kuwait, 128 days for Riyadh, and 107 days for Abu Dhabi, while it is only 53 for Muscat and 33 for Manama. Hence it is clear that cities located in the northern Arabian Peninsula are hotter than the cities in the Southern Peninsula. This result supports the CMIP5 and CMIP6 simulations, which show the Northern Peninsula warming faster than the Southern Peninsula (Almazroui et al. 2017b). The number of hot days with maximum temperature $\geq 45^{\circ} \mathrm{C}$ is almost the same for both annual and summer timescales, because the annual count of hot days comes mostly from summer months. The number of hot days shows an increasing trend for all GCC capitals except for Muscat, which has a decreasing trend (negative scale not shown). A large increase in the number of hot days is observed in Kuwait (12-day decade ${ }^{-1}$ on the annual and 10-day decade ${ }^{-1}$ on the summer timescales).

Percentile-based warm/cold days obtained from surface observations in six capital cities indicate that the local climate is warming in the GCC region (Fig. 10). All the GCC capital cities show more warm days (TX90p, TX95p, and TX99p) and fewer cold days (TX10p) except for Muscat, which shows insignificantly fewer warm days and significantly more cold days (Table 3). The discrepancy for Muscat may be due to the location of the data collection at the station or for some other reasons that need further investigation. Muscat is located at the coast of the Gulf of Oman, and its maximum temperature has a decreasing trend (see Fig. 2). Because the maximum temperature of Muscat has a decreasing trend, the temperature indices there show the opposite trends compared with other GCC capital cities where maximum temperatures are increasing. RegCM4 simulations show that for the entire analysis period from the present time (1978) to the end of the projection time (2099) under RCP8.5, the number of warm days increases and number of cold days decreases for all the GCC capital cities (Fig. 11). All GCC capital cities show increasing trend for warm days, except Manama shows very strong variability. The warm days trends are statistically significant at the $99 \%$ confidence level for Muscat and Doha, 95\% for Makkah and Madinah, and 90\% for Riyadh and Abu Dhabi. Manama shows inaccurate trend due to station location as Bahrain is an island surrounded by water body, which needs further investigation. The trends in warm and cold days for the current period 1978-2019 indicate that projected trends are reliable (Table 3). Overall, the increase rate of model simulated warm days is higher than the same obtained from the observations. Among the GCC capital cities, observations show that warm days are increasing at a faster rate over Kuwait and Manama which is supported by the faster decreasing of cold 

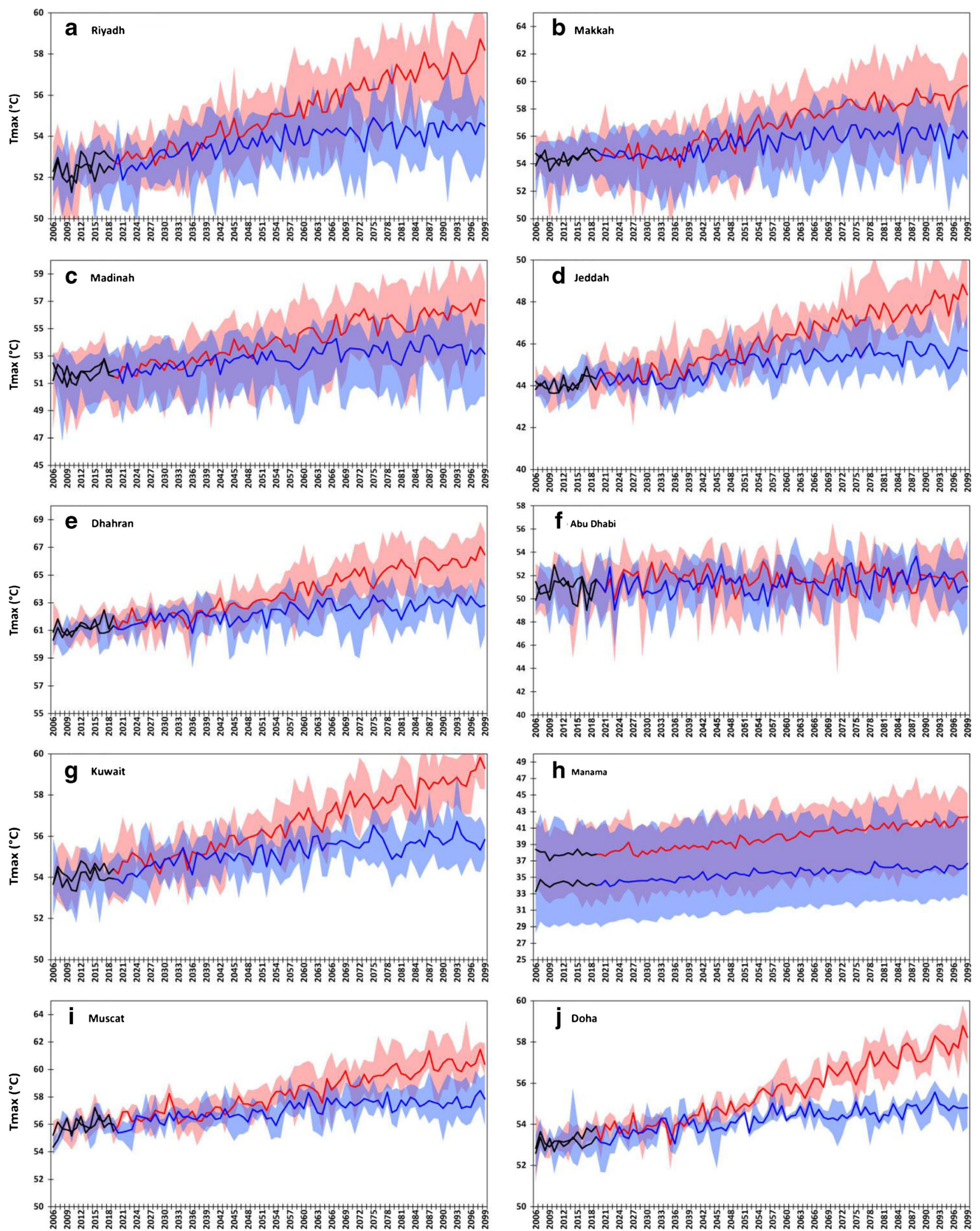
Fig. 13 The evolution of the projected maximum of summer maximum temperature (Extreme Tmax in ${ }^{\circ} \mathrm{C}$ ) with uncertainties (shaded) at six capital cities of GCC states and four major cities in Saudi Arabia under RCP4.5 (blue line) and RCP8.5 (red line) scenarios for the projection period 2006-2099 (solid line is the average from all datasets, black represents the running period, and red/blue represents the future period). The stations are (a) Riyadh, (b) Makkah, (c) Madinah, (d) Jeddah, (e) Dhahran, (f) Abu Dhabi, (g) Kuwait, (h) Manama, (i) Muscat, and (j)

days. Riyadh and Abu Dhabi show medium increase (decrease) rate of warm (cold) days, while Doha is the slowest one. Irrespective of magnitude, the sign of trends are the same for all GCC capital cities except for Muscat.

\section{Changes in summer maximum temperature in the twenty-first century}

The changes in adjusted average summer maximum temperature in the capital cities of the GCC states and some important cities in Saudi Arabia show an upward surge under RCP8.5 as compared with RCP4.5 (Fig. 12). Over most of the cities, the increase in adjusted average summer maximum temperature is projected to be about $5^{\circ} \mathrm{C}$ at the end of the twenty-first century and could exceed $12{ }^{\circ} \mathrm{C}$ at the upper end under RCP8.5 but might be as low as $2{ }^{\circ} \mathrm{C}$ at the lower end under RCP4.5. The lowest rise is expected for Abu Dhabi (about $9{ }^{\circ} \mathrm{C}$ ) while the highest rise is projected for Dhahran (possibly $\sim 15^{\circ} \mathrm{C}$ ). The rate of increase of adjusted ensemble average summer maximum temperature under RCP8.5 for the future period of 2020-2099 is above $0.6{ }^{\circ} \mathrm{C}$ decade $^{-1}$ at Riyadh, Makkah, Dhahran, Abu Dhabi, and Kuwait, while for RCP4.5 it is above $0.2{ }^{\circ} \mathrm{C}$ decade $^{-1}$ at Riyadh, Makkah, Jeddah, Dhahran, Abu Dhabi, Kuwait, and Doha (Table 4). The statistically significant rate of increase of adjusted summer maximum temperature is within the range of 0.49 (Manama) to 0.66 (Riyadh) ${ }^{\circ} \mathrm{C}$ decade ${ }^{-1}$ under RCP8.5, while it is within the range of 0.16 (Manama) to 0.27 (Makkah) ${ }^{\circ} \mathrm{C}$ decade $^{-1}$ under $\mathrm{RCP} 4.5$. Hence, it is clear that the increase in adjusted temperature over the capital cities of the GCC states varies from place to place, and estimates for one place cannot be applied to other places, especially for application-oriented purposes.

\section{Maximum of daily maximum temperature in the twenty-first century}

The maximum of daily maximum temperature (extreme Tmax) in a year is obtained from the highest temperature in a day over the year. This may exceed the SFHT limit of $42{ }^{\circ} \mathrm{C}$ for all the cities, except for Manama, under both RCP4.5 and RCP8.5 scenarios (Fig. 13). The extreme Tmax values exceed $50{ }^{\circ} \mathrm{C}$ for all the cities except for Manama and Jeddah for the period 2006-2099. Note that the spread shows the extreme
Tmax from three different driving GCMs and two different surface parameterization schemes. The lowest and the highest values of the extreme Tmax from these three by two matrices delimit the range of uncertainty. The lines represent the average from all six extreme Tmax values in a year. At the end of the twenty-first century, the extreme Tmax could approach and exceed $55^{\circ} \mathrm{C}$ in Riyadh, Makkah, Madinah, Kuwait, Muscat, and Doha, while it could reach $60^{\circ} \mathrm{C}$ under RCP8.5 in Kuwait, Abu Dhabi, and Muscat. Among all the cities, extreme Tmax is highest for Dhahran, which exhibits values over $60^{\circ} \mathrm{C}$ under both scenarios for the entire projected period starting from 2006. Overall, extreme Tmax results are in line with the findings of Pal and Eltahir (2016), who reported that without bias adjustment the extreme Tmax could exceed 60 ${ }^{\circ} \mathrm{C}$ at some places in the Peninsula. However, from Fig. 13, we can argue that extreme Tmax values exceeding $60^{\circ} \mathrm{C}$ for the verifiable period (2006 - 2019) in Dhahran and even values exceeding $55^{\circ} \mathrm{C}$ at Makkah, Abu Dhabi, Muscat, and Kuwait are not observed, which is different from the conclusion drawn from the abovementioned earlier studies. This disparity warrants further investigation by utilizing data from other driving GCMs and downscaling by using different RCMs, to reduce the uncertainty and enhance the reliability of summer maximum temperature projections over the region. To achieve this, regional coordination among the GCC states is needed to improve the quality of observations, and to develop the tools that make climate change research more useful and reliable for stakeholders and policymakers.

\section{Conclusions}

The present study investigates the Survivability for a Fit Human Threshold (SFHT) maximum temperature during the summer (June-August) over the six Middle Eastern countries known as the Gulf Cooperation Council (GCC) in the twenty-first century. An ensemble of three dynamically downscaled global climate models (ECHAM, GFDL, and HadGEM) available from the Coupled Model Intercomparison Project Phase 5 (CMIP5) under the mitigation (RCP4.5) and business-as-usual (RCP8.5) scenarios are used to analyze the future climate (20062099) over the region. Future temperature projections are adjusted by removing the bias estimated over the base period for six capital cities in the GCC states and four major cities of Saudi Arabia. The adjusted temperature is required for application-oriented tasks because model simulations of present climate show overestimation for some cities and underestimation for others. Based on these calculations, the adjusted average summer maximum temperature does not exceed $52{ }^{\circ} \mathrm{C}$ at the end of the twenty-first century over any capital cities in the GCC states and the four major cities in Saudi Arabia. 
However, the maximum of daily maximum temperature could exceed $50{ }^{\circ} \mathrm{C}$ for all the cities, except Manama and Jeddah. Moreover, the maximum of daily maximum temperature could reach $60{ }^{\circ} \mathrm{C}$ for Abu Dhabi, Kuwait, and Muscat, while it could exceed $60{ }^{\circ} \mathrm{C}$ for Dhahran at the end of the twenty-first century. However, as it can be seen in Fig. 13, the maximum of daily maximum temperature at Dhahran is above $60{ }^{\circ} \mathrm{C}$ from the beginning of the projection period (2006), which is not observed during the available observational period up to 2019. Moreover, the simulated maximum of daily maximum temperature is almost $55{ }^{\circ} \mathrm{C}$ at Makkah, Abu Dhabi, Kuwait, and Muscat for the period 2006-2019, which also are not observed. Therefore, these projections are likely to prove unrealistic because of large biases in the projections for the recent verifiable period of 2006-2019.

For the recent verifiable period of 2006-2019, the model simulations capture the warm/cold day metrics as obtained from observations quit well. The adjusted summer maximum temperature will likely cross the SFHT temperature limit of $42{ }^{\circ} \mathrm{C}$ at all capital cities of the GCC states and the four major cities in Saudi Arabia by the end of the twentyfirst century. This indicates that climate change has to be considered in the long-term planning of the region, since exceeding the SFHT limit will most likely cause human health-related casualties.

However, further investigations into the daily temperature are required by utilizing projection data from other GCMs and downscale by using RCMs. This can be initiated through regional coordinated research program among the GCC states, which will be complied with carrying out comprehensive and integrated climate change research that not only contributes to our fundamental understanding of climate change but also informs stakeholders and policymakers, to a high degree of confidence, about likely future climate changes in the region.

Acknowledgments The author would like to thank the General Authority of Meteorology and Environmental Protection (GAMEP), Saudi Arabia, and other GCC states for providing surface observational data. The author also extends his thanks to ICTP, Trieste, Italy, for providing RegCM4 and CMIP5 data. Computation work described in this paper was performed using Aziz Supercomputer at King Abdulaziz University's High Performance Computing Center, Jeddah, Saudi Arabia.

Open Access This article is licensed under a Creative Commons Attribution 4.0 International License, which permits use, sharing, adaptation, distribution and reproduction in any medium or format, as long as you give appropriate credit to the original author(s) and the source, provide a link to the Creative Commons licence, and indicate if changes were made. The images or other third party material in this article are included in the article's Creative Commons licence, unless indicated otherwise in a credit line to the material. If material is not included in the article's Creative Commons licence and your intended use is not permitted by statutory regulation or exceeds the permitted use, you will need to obtain permission directly from the copyright holder. To view a copy of this licence, visit http://creativecommons.org/licenses/by/4.0/.

\section{References}

Almazroui M (2011) Sensitivity of a regional climate model on the simulation of high intensity rainfall events over the Arabian Peninsula and around Jeddah (Saudi Arabia). Theor Appl Climatol 104:261276. https://doi.org/10.1007/s00704-010-0387-3

Almazroui M (2016) RegCM4 in climate simulation over CORDEXMENA/Arab domain: Selection of suitable domain, convection and land surface schemes. Int J Climatol 36:236-251. https://doi. org/10.1002/joc. 4340

Almazroui M, Islam MN, Jones PD, Athar H, Rahman MA (2012a) Recent climate change in the Arabian Peninsula: Seasonal rainfall and temperature climatology of Saudi Arabia for 1979-2009. Atmos Res 111:29-45. https://doi.org/10.1016/j.atmosres.2012.02.013

Almazroui M, Islam MN, Athar H, Jones PD, Rahman MA (2012b) Recent climate change in the Arabian Peninsula: Annual rainfall and temperature analysis of Saudi Arabia for 1978-2009. Int J Climatol 32:953-966. https://doi.org/10.1002/joc.3446

Almazroui M, Abid MA, Athar H, Islam MN, Ehsan MA (2013) Interannual variability of rainfall over the ArabianPeninsula using the IPCC AR4 Global Climate Models. Int J Climatol 33:23282340. https://doi.org/10.1002/joc.3600

Almazroui M, Islam MN, Dambul R, Jones PD (2014) Trends of temperature extremes in Saudi Arabia. Int J Climatol 34:808-826. https:// doi.org/10.1002/joc.3722

Almazroui M, Islam MN, Alkhalaf AK, Saeed F, Dambul R, Rahman MA (2016a) Simulation of temperature and precipitation climatology for the CORDEX-MENA/Arab domain using RegCM4. Arab J Geosci 9:13. https://doi.org/10.1007/s12517-015-2045-7

Almazroui M, Islam MN, Al-Khalaf AK, Fahad S (2016b) Best convective parameterization scheme within RegCM4 to downscale CMIP5 multi-model data for the CORDEX-MENA/Arab domain. Theo Appl Climatol 124:807-823. https://doi.org/10.1007/s00704-0151463-5

Almazroui M, Saeed F, Islam MN, Alkhalaf AK (2016c) Assessing the robustness and uncertainties of projected changes in temperature and precipitation in AR4 global climate models over the Arabian Peninsula. Atmos Res 182:163-175

Almazroui M, Saeed S, Nazrul IM, Khalid MS, Alkhalaf AK, Dambul R (2017a) Assessment of uncertainties in projected temperature and precipitation over the Arabian Peninsula: A comparison between different categories of CMIP3 models. Earth Syst Environ 1(1). https://doi.org/10.1007/s41748-017-0012-Z

Almazroui M, Islam MN, Saeed S, Alkhalaf AK, Dambul R (2017b) Assessment of Uncertainties in Projected Temperature and Precipitation over the Arabian Peninsula Using Three Categories of CMIP5 Multimodel Ensembles. Earth Syst Environ 1(1). https://doi.org/10.1007/s41748-017-0027-5

AlSarmi S, Washington R (2014) Changes in climate extremes in the Arabian Peninsula: analysis of daily data. Int J Climatol 34:1329 1345. https://doi.org/10.1002/joc.3772

Dee DP, Uppala SM, Simmons AJ, Berrisford P, Poli P, Kobayashi S, Andrae U, Balmaseda MA, Balsamo G, Bauer P, Bechtold P, Beljaars ACM, van de Berg L, Bidlot J, Bormann N, Delsol C, Dragani R, Fuentes M, Geer AJ, Haimberger L, Healy SB, Hersbach H, Hólm EV, Isaksen L, Kållberg P, Köhler M, Matricardi M, McNally AP, Monge-Sanz BM, Morcrette J-J, Park B-K, Peubey C, de Rosnay P, Tavolato C, Thépaut J-N, Vitart F (2011) The ERA-interim reanalysis: configuration and performance of the data assimilation system. Q J R Meteorol Soc 137:553-597

Donat MG, Peterson TC, Brunet M, King AD, Almazroui M, Kolli RK, Boucherf D, Al-Mulla AY, Nour AY, Aly AA, Nada TAA, Semawi MM, Dashti HAA, Salhab TG, Fadli KIE, Muftah MK, Eida SD, Badi W, Driouech F, Rhaz KE, Abubaker MJY, Ghulam AS, Erayah AS, Mansour MB, Alabdouli WO, Dhanhani JSA, 
Shekaili MNA (2014) Changes in extreme temperature and precipitation in the Arab region: long-term trends and variability related to ENSO and NAO. Int J Climatol 34:581-592. https://doi.org/10. 1002/joc. 3707

El-Fadli KI, Cerveny R, Burt CC, Eden P, Parker D, Brunet M, Peterson TC, Mordacchini G, Pelino V, Bessemoulin P, Stella JL, Driouech F, Wahab MMA, Pace MB (2013) World Meteorological Organization assessment of the purported world record $58 \mathrm{C}$ temperature extreme at El Azizia, Libya (13 September 1922). Bull Am Meteorol Soc 94:199-204

Giorgetta MA, Jungclaus J, Reick CH, Legutke S, Bader J, Böttinger M, Brovkin V, Crueger T, Esch M, Fieg K, Glushak K, Gayler V, Haak H, Hollweg H-D, Ilyina T, Kinne S, Kornblueh L, Matei D, Mauritsen T, Mikolajewicz U, Mueller W, Notz D, Pithan F, Raddatz T, Rast S, Redler R, Roeckner E, Schmidt H, Schnur R, Segschneider J, Six KD, Stockhause M, Timmreck C, Wegner J, Widmann H, Wieners K-H, Claussen M, Marotzke J, Stevens B (2013) Climate and carbon cycle changes from 1850 to 2100 in MPI-ESM simulations for the Coupled Model Intercomparison Project phase 5. J Adv Model Earth Syst 5:572-597

Glazer JL (2005) Management of Heatstroke and Heat Exhaustion. Am Fam Physician 71(11):2133-2140

Im E-S, Pal JS, Eltahir EAB (2017) Deadly heat waves projected in the densely populated agricultural regions of South Asia. Sci Adv 3: e1603322

IPCC (2013) A Special Report of Working Groups I and II of the Intergovernmental Panel on Climate Change: Managing the Risks of Extreme Events and Disasters to Advance Climate Change Adaptation - Summary for Policymakers. Cambridge University Press, Cambridge
Islam MN (2009) Rainfall and temperature scenario for Bangladesh. Open Atmos Sci J 3(1):93-103

Islam MN, Uyeda H (2007) Use of TRMM in determining the climatic characteristics of rainfall over Bangladesh. Remote Sens Environ 108(3):264-276

Islam MN, Almazroui M, Dambul R, Jones PD, Alamoudi AO (2015) Long-term changes in seasonal temperature extremes over Saudi Arabia during 1981-2010. Int J Climatol 35:1579-1592. https:// doi.org/10.1002/joc.4078

Knutson R, Ploshay JJ (2016) Detection of anthropogenic influence on a summertime heat stress index. Clim Chang 138:25-39

Lelieveld J, Proestos Y, Hadjinicolaou P, Tanarhte M, Tyrlis E, Zittis G (2016) Strongly increasing heat extremes in the Middle East and North Africa (MENA) in the 21st century. Clim Chang 137:245260. https://doi.org/10.1007/s10584-016-1665-6

Meehl GA, Washington WM, Arblaster JM, Teng AHH, Tebaldi C, Sanderson BN, Lamarque J-F, Conley A, Strand WG, White JB III (2012) Climate system response to external forcings and climate change projections in CCSM4. J Clim 25:3661-3683

Pal JS, Eltahir EAB (2016) Future temperature in southwest Asia projected to exceed a threshold for human adaptability. Nat Clim Chang 6:197-200

Parsons K (2006) Heat stress standard ISO 7243 and its global application. Ind Health 44:368379

Riahi K, Rao S, Krey V, Cho C, Chirkov V, Fischer G, Kindermann G, Nakicenovic N, Rafaj P (2011) RCP 8.5: A scenario of comparatively high greenhouse gas emissions. Clim Chang 109:33-57

Thomson AM, Calvin KV, Smith SJ, Kyle GP, Volke A, Patel P, Sabrina D-A, Ben B-L, Wise MA, Clarke LE, Edmonds JA (2011) RCP4.5: A pathway for stabilization of radiative forcing by 2100 . Clim Chang 109:77-94 